\title{
CACHIMBAS Y KITRAS: UN ACERCAMIENTO A LAS PRÁCTICAS FUMATORIAS DE GRUPOS ALFAREROS DEL CENTRO-SUR DE CHILE
}

\author{
CAROLINA A. BELMAR ${ }^{\mathrm{a}}$, SILVIA ALFARO ${ }^{\mathrm{b}}$, DOINA MUNITA ${ }^{\mathrm{c}}, \mathrm{XIMENA} \mathrm{ALBORNOZ}^{\mathrm{b}}$, \\ CAROLINA CARRASCO ${ }^{b}$, JAVIER ECHEVERRÍA ${ }^{d}$, RODRIGO MERA ${ }^{e}$, LEONOR ADÁN $^{t}$, \\ LUCIANA QUIROZ ${ }^{b}$, HERMANN M. NIEMEYER ${ }^{\circ} \&$ MARIA TERESA PLANELLA $^{e}$
}

\section{RESUMEN}

El registro de prácticas fumatorias tiene larga data en la zona centro-sur de Chile, donde la información arqueológica y etnohistórica marcan el inicio de estas actividades para el período Alfarero Temprano hasta momentos históricos. Dada la amplitud temporal de esta práctica, se estudiaron la morfología y la decoración de doce pipas fumatorias con contexto de procedencia conocido y se analizaron los residuos de uso para identificar los elementos introducidos y/o fumados en ellas. Considerando la importancia del humo en el mundo mapuche, también se incluyó en el estudio un jarro (pichimetawe) de seis bocas que podría haber sido usado en la emanación de humo, y una pieza de función indeterminada. Se logró verificar la existencia de siete formas de pipas para el área, de las cuales tres cuentan con información contextual. Se identificó la presencia de Nicotiana sp., Cyperaceae y cf. Latua pubiflora en el contenido de algunas de las piezas analizadas.

PALABRAS CLAVE: Complejo fumatorio, análisis de residuos, región centro-sur de Chile, pipas.

\section{CACHIMBAS AND KITRAS: AN APPROACH TO THE SMOKING PRACTICES OF THE CERAMIC GROUPS OF THE CENTER-SOUTHERN AREA OF CHILE}

\footnotetext{
ABSTRACT

Archaeological and ethnohistorial data show that smoking practices in the central-southern region of Chile begins during the Early Ceramic period and continue until historical times. In view of this long time span, twelve smoking pipes were studied: their morphology and decoration were determined, and use residues were analyzed to unravel the elements consumed. Considering

a Departamento Antropología, Universidad de Chile. Av. Capitán Ignacio Carrera Pinto №1045, Nunñoa, Santiago. carolina_belmar@hotmail.com

b Investigadora independiente. karenssa@hotmail.com, ximena.albornoz@gmail.com, carolina.carrasco.lagos@gmail.com, lucianaquiroz@hotmail.com.

c Departamento de Antropología, Facultad de Ciencias Sociales, Universidad Católica de Temuco. doinamunita@yahoo.com

d Facultad de Química y Biología, Universidad de Santiago, Chile. javier.echeverriam@usach.cl

e Sociedad Chilena de Arqueología. meragol@gmail.com; mtplanella@gmail.com

f Dirección de vinculación con el medio, Universidad Austral de Chile. ladan@uach.cl

s Facultad de Ciencias, Universidad de Chile.niemeyer@abulafia.ciencias.uchile.cl
} 
the importance of smoke in the mapuche world, a pichimetawe and an undetermined ceramic fragment where also studied. Results show seven types of smoking pipes for the area. It was possible to identify the presence of Nicotiana sp., Cyperaceae and cf. Latua pubiflora in some of these artifacts.

KEY WORDS: smoking complex, residue analysis, central-southern region of Chile, smoking pipes.

\section{INTRODUCCION}

Los antecedentes sobre la presencia de los complejos fumatorios en Chile se apoyan en la aparición de pipas durante el período Alfarero Temprano y el consumo generalizado de Nicotiana spp. (Planella et al. 2012; Quiroz et al. 2012; Echeverría et al. 2014; Carrasco et al. 2015; Belmar et al. 2016; Quiroz et al. 2016; Gili et al. 2017). En el área centro-sur de Chile, la presencia de elementos vinculados a las tradiciones fumatorias se extiende hasta tiempos históricos. Asimismo, se cuenta con relevante información etnográfica y etnohistórica referida a estas prácticas (véase Planella et al. 2016). Esta continuidad de uso es un hecho particular que no se registra en el norte semiárido ni en la zona central de Chile, y es principalmente explicado por la ausencia de grupos étnicos originarios debida a desplazamientos forzados vinculados a momentos históricos. En ese sentido, el acceso a este tipo de costumbres en la zona centro-sur de Chile nos acerca a detectar continuidades y cambios asociados a ellas, por ejemplo a través de posibles variaciones en los tipos de pipas y sus decoraciones, y de lo que se consumió en ellas.

Los registros documentales en el área de estudio señalan varias denominaciones para las pipas, tales como kütras (Guevara, 1911), kitra (De Augusta, 1992[1916]) y quichras, quitras y cütras (Latcham, 1936). En relación con el acto de fumar, Guevara (1911) señala que la palabra pütrem se refiere a toda sustancia fumable $y$ pütremen o pütremtun al acto de absorber el humo, quemar algo que echa humo y al mismo acto de fumar (Guevara \& Oyarzún, 1912). Sin duda, las diversas fuentes destacan la importancia del tabaco y del humo en la ejecución de ceremonias como nguillatun, juntas de rogativas, invocaciones, ritos de sanaciones y de iniciación de machi, conjuros, alianzas de paz o lúdico-domésticas (Núñez de Pineda \& Bascuñán, 1863[1637]; Molina, 2000 [1788]; Rosales, 1877-1878; Medina, 1898; Guevara, 1911; Guevara \& Oyarzún, 1912; Joseph, 1931; Serrano, 1934; Latcham, 1936; Housse, 1940; Cooper, 1949; Titiev, 1951; Falkner, 1957; Möesbach, 1992[1959]; Föerster, 1985; Erize, 1987; Gundermann, 1985; Föerster, 1995; Föerster \& Gundermann, 1996). Incluso existen referencias de ritos de sanación o machitún, donde una machi hace de oficiante y utiliza el humo de una quitra (Núñez de Pineda \& Bascuñán, 1863[1637]; Molina, 2000 [1788]; Guevara, 1911; Métraux, 1942; Faron, 1964; Dowling, 1971; Citarella, 1995).

Frente a este cúmulo de información, resulta relevante indagar, a través del registro arqueológico, en algunas dimensiones del fumar en el área centrosur, que nos permita profundizar en su compresión como una práctica generalizada desde el período Alfarero Temprano hasta tiempos históricos. Para ello, primero expondremos antecedentes arqueológicos inéditos de la proveniencia de las pipas, para luego describir sus morfologías y decoraciones. Posteriormente, entregaremos los resultados de los análisis de los residuos de uso, específicamente la evidencia microfósil y química, que indican qué elementos fueron introducidos y/o fumados en las pipas. Tomando en cuenta la importancia del humo en el mundo mapuche, y considerando al Complejo Pitrén como parte de su sustrato cultural, también se incluyó en el análisis una pieza que sugiere su uso en la emanación de humo, correspondiente a un jarro (pichimetawe) de seis bocas, del sitio Villa JMC-1, Labranza.

\section{ANTECEDENTES}

Si bien se conoce la abundancia de pipas para el área centro - sur de Chile, son pocas las que efectivamente cuentan con datos de procedencia. Se revisaron las colecciones depositadas en el 


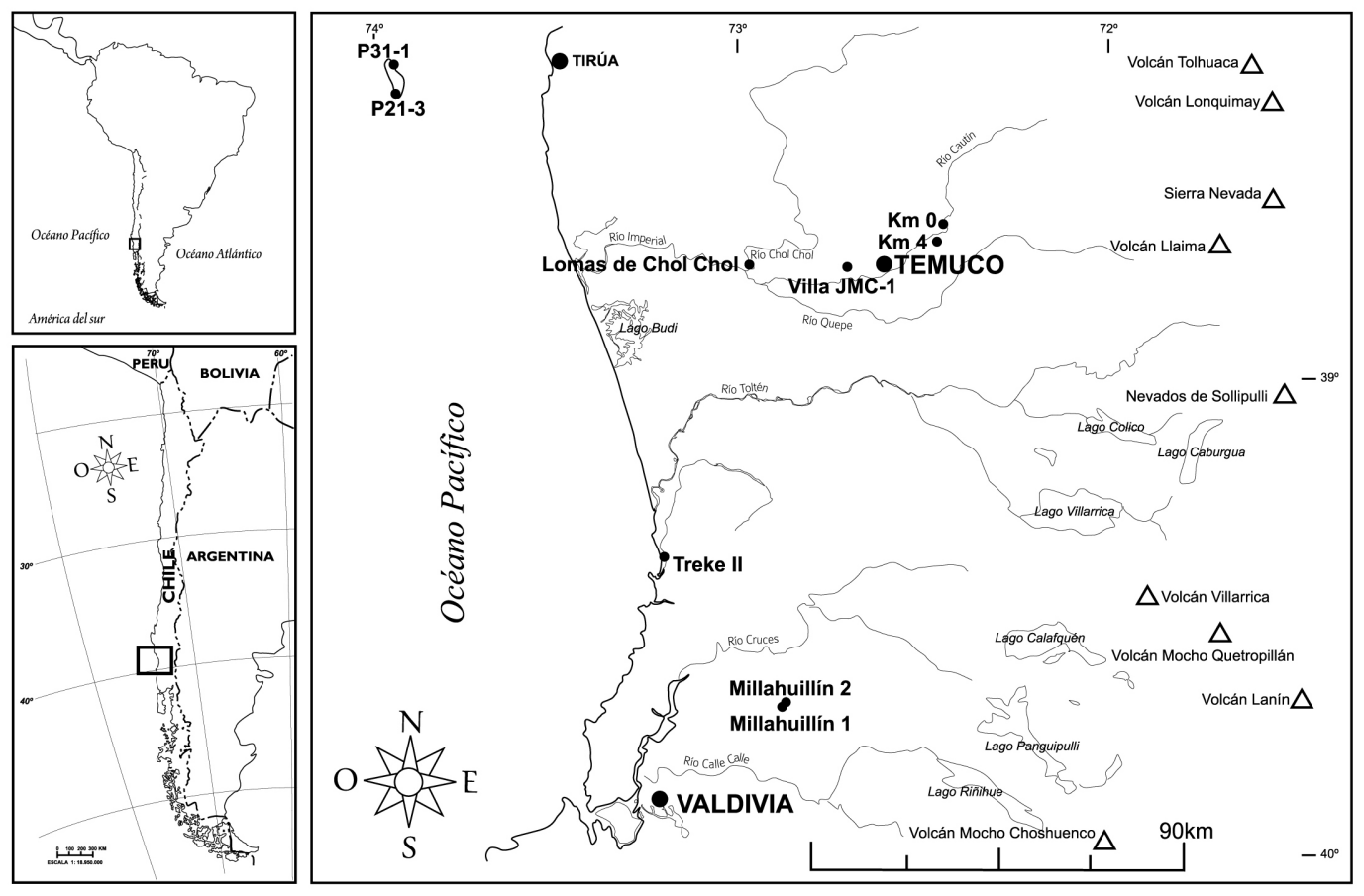

Fig. 1. Mapa de localización de sitios con pipas estudiadas de la zona centro-sur de Chile.

Museo Regional de la Araucanía, Museo Histórico y Antropológico Mauricio Van de Mäele y Museo Mapuche de Cañete. Del total de 132 pipas registradas en estos museos, solo tres efectivamente contaban con los datos necesarios para ubicarlas espacial y temporalmente; por lo tanto, recurrimos a piezas recuperadas de excavaciones vinculadas a proyectos de investigación y de impacto ambiental, logrando contextualizar 12 fragmentos de pipas. Las piezas muestreadas provienen de nueve sitios arqueológicos distribuidos en el valle central y en la isla Mocha (Fig. 1). A la fecha, estos yacimientos -ubicados cronológicamente entre los 1100 y los 300 años AP (Tabla 1)- se encuentran en distintas fases de investigación, aportando información disímil acerca de sus contextos. La pieza analizada de Villa JMC-1, Labranza es la única del período Alfarero Temprano (PAT), mientras que las demás han sido asociadas a los períodos Alfarero Tardío y Colonial.

El sitio Villa JMC-1, Labranza se emplaza en la sección media del río Cautín, a unos 10 $\mathrm{km}$ al oeste de Temuco, región de La Araucanía (Mera \& Munita, 2008; Mera, 2014). El ambiente corresponde a una terraza fluvial amplia, que hasta hace poco tiempo aún conservaba lagunas y humedales de tamaño importante. Corresponde a un cementerio que fue encontrado producto de la construcción de viviendas sociales, reconociendo una superficie para el yacimiento de unos 200 $\mathrm{m}^{2}$ aprox. Se registraron 48 contextos funerarios y restos bioantropológicos de 23 individuos en muy mal estado de conservación, todos ellos en asociación a conjuntos de ofrendas. Como parte de los ajuares se identificaron aros de cobre de alta pureza (Munita et al. 2011; Mera et al. 2015) y cuentas sobre valvas de ostión (Pecten sp.), cerámica, lutitas y otras materias primas líticas (Bracchitta \& Seguel, 2009; Mera, 2014). Dentro de las ofrendas destaca toda la ergología de vasijas Pitrén (Adán, 2000; Ocampo et al. 2004; Mera \& Munita, 2006), mayormente monocromas y algunas con técnica resistente (negativa), con modelados anfibiomorfos, antropomorfos y biomorfos y botellas con asas de suspensión, entre otras.

Previo a la realización de este trabajo fueron estudiados los microfósiles de residuos adheridos en dos pipas cerámicas recuperadas de este sitio, constatando la presencia diferencial de almidones y silicofitolitos en los hornillos y tubos/boquilla de las pipas, y observando mayor cantidad de almidones y diversidad de microfósiles en las 
C. A. BELMAR et al.

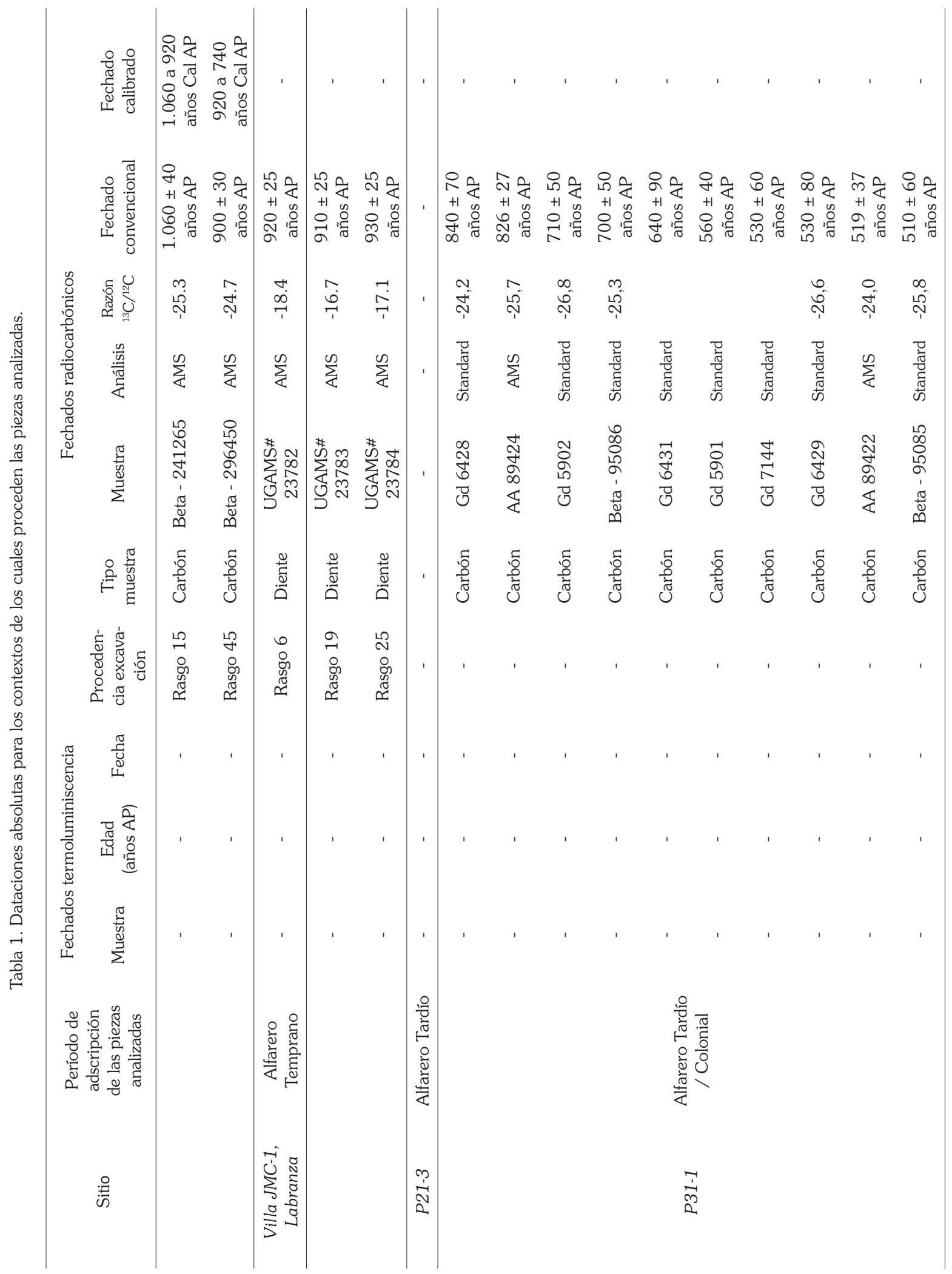




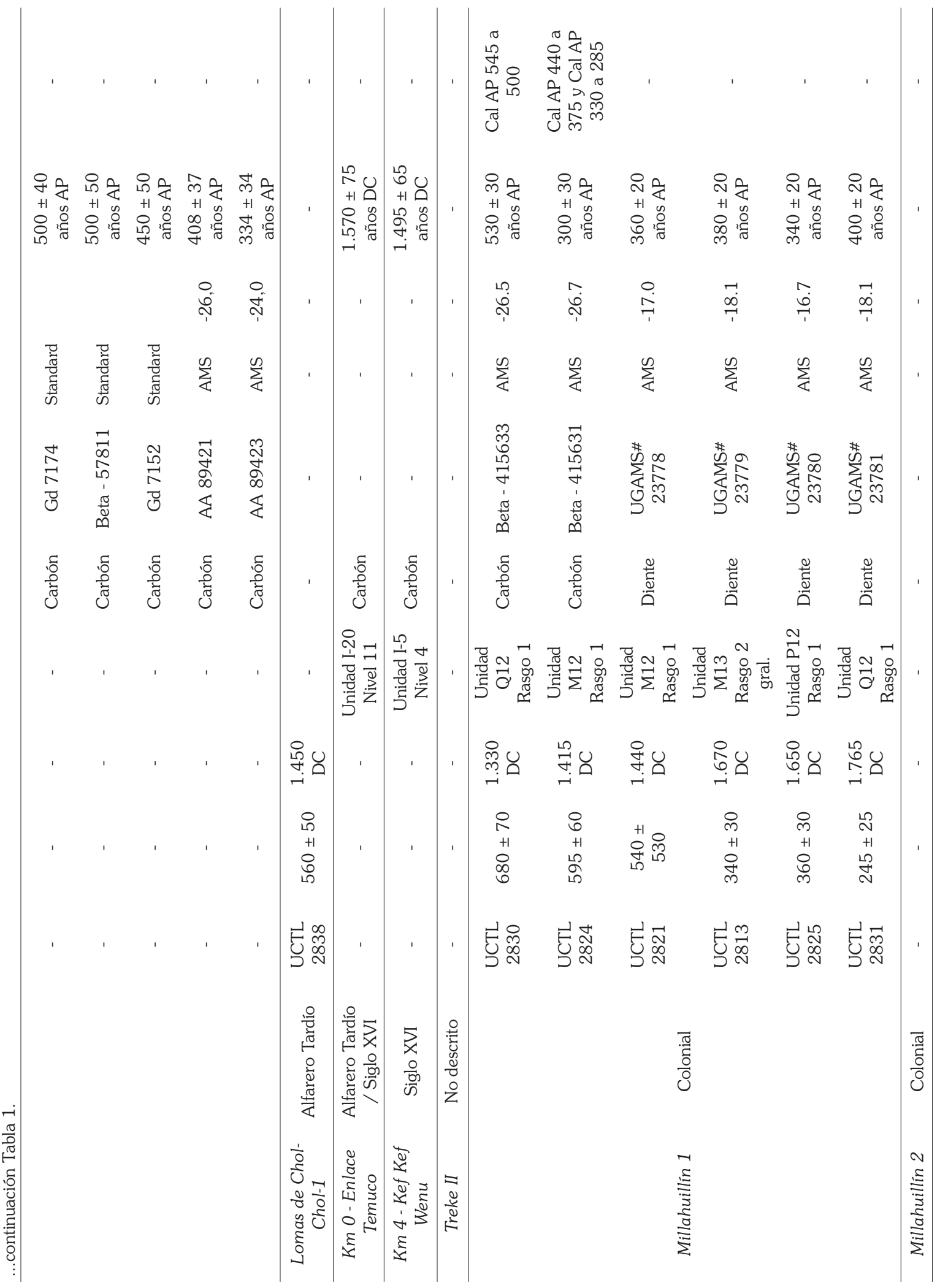


boquillas que en los hornillos. Entre los taxones identificados destacan morfotipos adscritos a Poaceae y Solanaceae, además de almidones simil Nicotiana sp. y Solanum sp. (Quiroz et al. 2012).

Por su parte, la pieza analizada en el sitio Villa JMC-1, Labranza forma parte de un contexto fúnebre (rasgo 23) en el que se recuperaron cinco vasijas, correspondientes a dos jarros simétricos (Tipo 1, Adán, 2000), una olla de base plana (Tipo 6, op. cit.), un jarro simétrico sin decoración (Tipo 15, op. cit.), una lasca, una argolla/aro de cobre y una cuenta lítica circular probablemente de lutita. La pieza estudiada corresponde a un modelado complejo (de acuerdo con el Tipo 18, op. cit.) descrito inicialmente como un jarro pequeño con seis bocas (Mera \& Munita, 2008).

En el área insular, el sitio P21-3 corresponde a un denso conchal que supera los dos metros de potencia y se ubica en el extremo sur de la isla Mocha, comuna de Lebu, Provincia de Arauco, región del Bío Bío. Se excavaron niveles históricos y alfareros tardíos (Matisoo-Smith et al. 2011), confirmando la complejidad de los contextos ya descritos en trabajos anteriores (Quiroz \& Sánchez, 1997). Las diferentes áreas excavadas en Parcela 21 se encuentran emplazadas en la parte baja de una ladera de cerro, separada de la terraza marina III por un escarpe de erosión, en una cota cercana a los $25 \mathrm{msnm}$ (Prieto, 1997, p. 97). Así como en P21-1/P21-2 fueron registrados componentes habitacionales y funerarios, en P21-3 se halló el entierro de un infante en una urna funeraria, en los niveles adscritos para el Alfarero Tardío, observando la integración del componente funerario en un locus de actividades domésticas. No solo este aspecto es similar a los contextos anteriormente descritos de la Parcela 21, también los restos de consumo y los materiales culturales se asocian directamente a las industrias identificadas, destacando instrumentos diagnósticos como piezas metálicas con contenido de cobre, una cuenta en materia prima lítica de color verde, cuentas carbonizadas -aparentemente elaboradas en materiales orgánicos-, "palas" en huesos de cetáceos, como las halladas en P31 (Becker, 1997), diversos instrumentos de hueso como agujas, anzuelos y punzones, fragmentos incisos y otros pulidos, sin decoración y de funcionalidad indefinida, una tortera ósea de morfología muy similar a las registradas para la cultura Diaguita, un yunque lítico y cuchillos en valvas de mitílidos. Este sitio se encuentra en proceso de investigación y las características aquí descritas solo corresponden a algunos elementos registrados durante su excavación. Las pipas analizadas fueron recuperadas en los niveles inferiores de la ocupación del Alfarero Tardío en el conchal, entre los 150 y $190 \mathrm{~cm}$ de profundidad.

También en Isla Mocha, otro sitio es P31-1, uno de los más investigados de la isla. Se encuentra a $50 \mathrm{msnm}$ aproximadamente y ocupa una extensa área descrita como campo de dunas (Prieto, 1997) de la terraza litoral, entre el piedemonte y el borde costero. En términos arqueológicos, fue caracterizado inicialmente por el equipo de trabajo de los proyectos FONDECYT 1921192 y 1950175 (Quiroz \& Sánchez, 1997), siendo reevaluado por Campbell (2011), quien lo identifica como un centro político (una posible jefatura) en el lado oriente de la isla, siendo probablemente una de las áreas más visitadas por los europeos durante la Colonia. Por otra parte, las evidencias arqueológicas y etnohistóricas demostrarían una funcionalidad compartida, residencial y ritual para el sector definido arqueológicamente como P31-1 (op. cit., 49). La pieza analizada en este trabajo fue recuperada en el nivel 20-30 de la capa 1.

Refiriéndonos nuevamente a yacimientos en el continente, el sitio Lomas de Chol-Chol 1 se ubica próximo a la ciudad de Nueva Imperial, en la región de La Araucanía. Se emplaza en la cima de un sistema de cerros que delimita el valle del río CholChol por el noroeste en este tramo (Hermosilla, 2006). Corresponde a un sitio habitacional, adscrito crono-culturalmente al período Alfarero Tardío. En cuanto a las características del yacimiento, éste evidencia procesos post-depositacionales que afectaron el depósito (fundamentalmente un intenso pisoteo), lo que se tradujo en rasgos muy disturbados y una alta fragmentación y erosión del material cerámico (Donoso, 2013). Dentro del conjunto alfarero, los tipos decorativos distintivos 
y con una relativa alta presencia son los incisos (lineales, cuneiformes y punteados) y las lentejuelas al pastillaje, además de las piezas con engobe. Por otra parte, el conjunto lítico, desde una perspectiva funcional, refleja la realización de una serie de labores de índole doméstica asociadas a un asentamiento multifuncional que involucraría cierta permanencia o intensidad en el tiempo, denotadas especialmente en la explotación y descarte in situ de recursos pétreos locales (Peralta, 2008). En relación a las pipas, se recuperó una pipa completa y un fragmento de pipa, ambas de cerámica y recolectadas de la superficie.

De los yacimientos arqueológicos excavados en el marco de la construcción del By Pass de Temuco, destaca el sitio Km 0-Enlace Cajón (Ciprés Consultores, 2002); en él se identificaron los restos de una ruka mapuche de momentos del contacto entre las poblaciones local e hispana. Se excavó un volumen de 44 $\mathrm{m}^{3}$, distribuidos en un área de $105 \mathrm{~m}^{2}$, donde se registró la presencia de 25 hoyos de poste, varios de ellos alineados y probablemente relacionados con las diferentes habitaciones de la ruka; fogones de distintas dimensiones con materiales asociados, y bolsones de diversa planta y profundidad con restos relacionados, siendo varios de ellos interpretados como basureros. Entre los restos culturales rescatados destaca la presencia de un hacha en piedra pulida, variados instrumentos y artefactos sobre obsidiana, sílices y principalmente basalto y andesita; manos de moler, cuchillos y raspadores; una punta de proyectil fracturada de morfología tardía; una pequeña olla cerámica, y un aro rectangular con muesca fracturado, elaborado en bronce $(\mathrm{Cu}+$ As) (Munita et al. 2011). La presencia de restos

1 La challa u olla en mapuzungun, se caracteriza por su monocromía café, ahumada o negra y la decoración modelada o incisa en la zona del cuello, formando una secuencia de acanaladuras horizontales o rodetes (piulos) delimitados entre sí, elemento denominado también como estriamiento anular (p.ej. Aldunate 1989, p. 340, Fig. 4c). Como piezas diagnósticas de grupos de filiación mapuche, se las ha identificado desde momentos prehispánicos, evidenciando escasas o nulas influencias externas (hispana, incaica) para momentos coloniales en el Wallmapu.

2 Pihuelo es la pieza metálica que sujeta y de donde giran las rodajas de la espuela. La palabra pihuelo deriva materiales de mayor tamaño en un sector del sitio, muchos de ellos con hollín en la superficie, y de un "leño" quemado sobre las improntas de hoyos de poste, podrían dar cuenta de una situación de abandono producto de algún evento catastrófico (probablemente un incendio). A pesar de la gran cantidad de materiales recuperados en el sitio, la unidad de procedencia de la pipa analizada en este trabajo (cuadrícula $\mathrm{J} 13$, entre los 0 y $30 \mathrm{~cm}$ ) se distinguió por la escasa presencia de restos arqueológicos y la ausencia de otros rasgos (Ocampo et al. 2005).

Registrado y rescatado también en el marco de la construcción del By Pass de Temuco, el sitio Km 4-Kef Kef Wenu corresponde a un asentamiento habitacional de características mapuche histórico coloniales. Presenta dos sectores de mayor intensidad de ocupación y evidencia rasgos domésticos de habitación, preparación y consumo de alimentos, tales como fogones y concentración de piedras de moler. A su vez, se encuentran fragmentos cerámicos diagnósticos con círculos incisos, pintura blanca sobre rojo, roja sobre blanca y cuellos de challa ${ }^{1}$, entre otros. Destaca también un fragmento metálico correspondiente al pihuelo ${ }^{2}$ de un estribo, elemento asociable al complejo ecuestre ${ }^{3}$. Por su parte, se identificó material lítico pulido y tallado, realizado en materias primas locales (principalmente sílices y basaltos, etc.) y de procedencia más alejada (obsidianas). Inicialmente, este sitio fue interpretado como un contexto histórico tardío, aunque el fechado radiocarbónico obtenido, así como la observación más detallada de las evidencias materiales, dan cuenta de la necesidad de reevaluar estas primeras interpretaciones. La pipa analizada fue recuperada de la superficie del sitio.

de "pihuela", que eran unas correas con las cuales amarraban los pies de los prisioneros para dificultarle el movimiento y prevenir su huída". (http://etimologias. dechile.net/?pihuelo)

3 La temprana adopción del caballo por parte de los grupos culturales locales en la Araucanía y las pampas (siglo XVI) involucró la incorporación de una serie de rasgos culturales denominados como "complejo ecuestre" en América (Nardi, 1981-82, p. 13). Estos rasgos aún no han sido asumidos en términos arqueológicos en el sur de Chile debido a la escasez de evidencias materiales relevadas, por lo que los registros de Km4-Kef Kef Wenu plantean un tema de investigación pendiente. 
Aunque no se cuenta con mayores descripciones, el sitio Treke II fue registrado en el marco del proyecto "Evolución del impacto del hombre en ecosistemas litorales marinos" (Sanhueza, 1989), en el área costera -lafkenchede Queule, provincia de Cautín, región de La Araucanía, se habrían observado y descrito las actividades económicas de la comunidad local, especialmente la recolección marina, esperando correlacionar dichos resultados con excavaciones arqueológicas (op. cit.). En este trabajo se analizó un fragmento cerámico indefinido que fue recuperado de la superficie del sitio.

Más al sur, el sitio Millahuillín 1, ubicado en la comuna de Máfil, región de Los Ríos, corresponde a un cementerio mapuche asociado a la tradición bícroma (estilo Valdivia). Se encuentra emplazado en el aterrazamiento de una loma que es parte de un sistema de cerros que rodean humedales asociados a las extensas llanuras aluviales de la cuenca media del río Cruces.

La interpretación de los datos aportados por Millahuillín 1 permite dar cuenta, en términos arqueológicos, de las costumbres fúnebres y el habitar por parte de los grupos mapuche-huilliche o reche-mapuche (Adán, 2014) durante los tres siglos previos a la instalación de la República, no solo con relación a la inhumación de los individuos, sino también de la ritualidad llevada a cabo en el cementerio, ratificando referencias históricas como el uso de estructuras de madera en los enterratorios (uso de tablones y depositación de ofrendas ovinas, ambas costumbres referidas en $E l$ cautiverio feliz de Núñez de Pineda y Bascuñan (1863[1637]), otorgándole una profundidad mayor y un correlato material y arqueológico a datos etnohistóricos.

Las dos piezas analizadas en este trabajo fueron recuperadas mediante el harneo sistemático de los sedimentos removidos durante las faenas forestales que suscitaron el hallazgo del sitio. Asimismo, la pipa analizada del sitio Millahuillín 2 -emplazado a aproximadamente a $1,2 \mathrm{~km}$ de Millahuillín 1 - fue recuperada de los sedimentos removidos $e$ inspeccionados durante el peritaje arqueológico (Adán, 2012). En este sitio, además de la pieza muestreada, las

4 Por medidas de conservación, el análisis de pastas no se pudo realizar puesto que requiere extraer un pequeño vasijas completas dan cuenta de un cementerio. En los sedimentos removidos se identificaron jarros con engobe rojo, una olla monocroma con estriamiento anular en el cuello (challa) y un excepcional vaso Valdivia con morfología de copa, de influencia hispana.

Ambos sitios, Millahuillín 1 y 2, evidencian contextos funerarios de la cultura mapuchehuilliche, con diferentes elementos diagnósticos de relaciones interétnicas locales ancestrales/ hispanas, durante tiempos coloniales en la Jurisdicción de Valdivia, dando cuenta de las actividades fumatorias del período.

\section{METODOLOGÍA}

\section{Análisis cerámico y muestra de estudio}

Para realizar el análisis se utilizaron variables orientadas a caracterizar los atributos morfológicos y decorativos observados en cada una de las pipas ${ }^{4}$ (Planella et al. 1995; Alfaro, 2013); además, para los ejemplares completos o poco fracturados se utilizó la tipología elaborada durante el desarrollo del proyecto FONDECYT 1121097 (Alfaro, 2015), en el cual se ficharon las pipas cerámicas facilitadas por diferentes museos y proyectos. Es importante mencionar que para el área sur ya se había propuesto una tipología (Ortiz, 1968) que, a diferencia de la nuestra, incluyó tanto las pipas cerámicas como líticas, generando un número significativo de tipos al clasificarlas por rasgos tecnológicos que en ese momento fueron considerados como diferenciadores, pero que en nuestro trabajo fueron integrados en una misma categoría.

Ambas tipologías fueron posibles de realizar debido a que las muestras a partir de las cuales se elaboraron presentan un muy buen estado de conservación; sin embargo, para la mayoría de estas pipas no se cuenta con los datos de sus contextos ni tampoco referencias de los lugares desde donde fueron recuperadas, lo que se ha transformado en una gran desventaja al no poder, por ejemplo, relacionar uno o más tipos con un grupo cultural específico, establecer si existe alguna diferenciación regional o si hay una continuidad temporal o no en el tipo de pipa utilizada, salvo en

fragmento de la pipa para poder identificar en el corte fresco los antiplásticos presentes. 
Tabla 2. Caracterización de los sitios y procedencia de las piezas analizadas. A=arqueobotánico; $Q=$ químico.

\begin{tabular}{|c|c|c|c|c|c|c|c|c|}
\hline \multirow[t]{2}{*}{ Sitio } & \multirow[t]{2}{*}{ Emplazamiento } & \multicolumn{2}{|c|}{$\begin{array}{c}\text { Coordenadas (Datum } \\
\text { WGS 84) }\end{array}$} & \multirow{2}{*}{$\begin{array}{l}\text { Funcionalidad } \\
\text { del sitio }\end{array}$} & \multirow{2}{*}{$\begin{array}{c}\text { Descripción del } \\
\text { artefacto }\end{array}$} & \multirow{2}{*}{$\begin{array}{l}\text { Análisis } \\
\text { del } \\
\text { residuo }\end{array}$} & \multirow{2}{*}{\multicolumn{2}{|c|}{$\begin{array}{l}\text { Procedencia intra- } \\
\text { sitio }\end{array}$}} \\
\hline & & UTM este & UTM norte & & & & & \\
\hline \multirow[b]{2}{*}{$\begin{array}{c}\text { Villa } \\
\text { JMC-1, } \\
\text { Labranza }\end{array}$} & \multirow[b]{2}{*}{$\begin{array}{l}\text { Segunda } \\
\text { terraza estero } \\
\text { Botrolhue, } \\
\text { Labranza. } \\
\text { Región de la } \\
\text { Araucanía }\end{array}$} & \multirow[b]{2}{*}{696.333} & \multirow[b]{2}{*}{5.707 .448} & \multirow[b]{2}{*}{$\begin{array}{c}\text { Cementerio. } \\
\text { Alfarero } \\
\text { Temprano }\end{array}$} & Jarro de seis bocas & $\mathrm{A} / \mathrm{Q}$ & \multicolumn{2}{|c|}{ Rasgo 23} \\
\hline & & & & & $\begin{array}{l}2 \text { pipas cerámicas: } \\
\text {-T invertida con } \\
\text { mamelón en la } \\
\text { base del hornillo } \\
\text {-T invertida } \\
\text { con mamelón } \\
\text { perforado en base } \\
\text { del hornillo }\end{array}$ & & \multicolumn{2}{|c|}{$\begin{array}{l}\text { Rasgo } 4 \text { y sin } \\
\text { contexto }\end{array}$} \\
\hline \multirow{2}{*}{ P21-3 } & \multirow{2}{*}{$\begin{array}{l}\text { Piedemonte en } \\
\text { contacto con } \\
\text { terraza marina, } \\
\text { isla Mocha. } \\
\text { Región del } \\
\text { Bio-Bío. }\end{array}$} & \multirow{2}{*}{596.218} & \multirow{2}{*}{5.748 .105} & \multirow{2}{*}{$\begin{array}{l}\text { Conchal con } \\
\text { depósito de } \\
\text { actividades } \\
\text { domésticas } \\
\text { y funerarias, } \\
\text { Alfarero Tardío }\end{array}$} & $\begin{array}{l}\text { Fragmento de } \\
\text { pipa/ lítico, tubo } \\
\text { abierto (tipo } \\
\text { indeterminado) }\end{array}$ & $\mathrm{A} / \mathrm{Q}$ & \multirow{2}{*}{$\begin{array}{c}\text { Unidad } \\
\text { excavación } \\
\text { 100A }\end{array}$} & $\begin{array}{c}150- \\
160 \mathrm{~cm}\end{array}$ \\
\hline & & & & & $\begin{array}{l}\text { Fragmento de } \\
\text { pipa cerámica/ } \\
\text { boquilla (tipo } \\
\text { indeterminado) }\end{array}$ & $\mathrm{A} / \mathrm{Q}$ & & $\begin{array}{c}180- \\
190 \mathrm{~cm}\end{array}$ \\
\hline P31-1 & $\begin{array}{l}\text { Campo de } \\
\text { dunas en el } \\
\text { litoral costero, } \\
\text { isla Mocha. } \\
\text { Región del } \\
\text { Bio-Bío }\end{array}$ & 594.649 & 5.755 .001 & $\begin{array}{c}\text { Sitio complejo } \\
\text { (habitacional, } \\
\text { ritual, } \\
\text { productivo), } \\
\text { Alfarero Tardio } \\
\text { Colonial }\end{array}$ & $\begin{array}{l}\text { Fragmento de } \\
\text { pipa cerámica/ } \\
\text { boquilla (tipo } \\
\text { indeterminado) }\end{array}$ & $\mathrm{A} / \mathrm{Q}$ & $\begin{array}{r}\text { Unidad de ex } \\
28,20-3\end{array}$ & $\begin{array}{l}0 \mathrm{~cm} \\
\text { cavación }\end{array}$ \\
\hline \multirow{2}{*}{$\begin{array}{l}\text { Lomas } \\
\text { de Chol- } \\
\text { Chol-1 }\end{array}$} & \multirow{2}{*}{$\begin{array}{l}\text { Cima de cerro } \\
\text { adyacente } \\
\text { al río Chol- } \\
\text { Chol, Nueva } \\
\text { Imperial. } \\
\text { Región de la } \\
\text { Araucanía. }\end{array}$} & \multirow{2}{*}{676.100} & \multirow{2}{*}{5.709 .250} & \multirow{2}{*}{$\begin{array}{l}\text { Habitacional, } \\
\text { Alfarero Tardío } \\
\text { (prehispánico) }\end{array}$} & $\begin{array}{c}\text { Fragmento de pipa } \\
\text { cerámica/tubo } \\
\text { abierto (tipo inde- } \\
\text { terminado) }\end{array}$ & $\mathrm{A} / \mathrm{Q}$ & \multicolumn{2}{|c|}{ Superficial } \\
\hline & & & & & $\begin{array}{l}\text { Pipa cerámica: } \\
\text {-T invertida con } \\
\text { mamelón en la } \\
\text { base del hornillo }\end{array}$ & $\mathrm{A} / \mathrm{Q}$ & \multicolumn{2}{|c|}{ Superficial } \\
\hline $\begin{array}{c}\mathrm{Km} \\
\text { 0-Enlace } \\
\text { Temuco }\end{array}$ & $\begin{array}{l}\text { Terraza } \\
\text { fluvial/aluvial } \\
\text { río Cautín, } \\
\text { Temuco. } \\
\text { Región de la } \\
\text { Araucanía }\end{array}$ & 718.634 & 5.717 .444 & $\begin{array}{c}\text { Habitacional } \\
\text { (ruka), Alfarero } \\
\text { Tardío, siglo } \\
\text { XVI }\end{array}$ & $\begin{array}{l}\text { Fragmento de } \\
\text { pipa cerámica/ } \\
\text { boquilla (tipo } \\
\text { indeterminado) }\end{array}$ & $\mathrm{A} / \mathrm{Q}$ & \multicolumn{2}{|c|}{$\begin{array}{l}\text { Unidad excavación } \\
\text { J13, 0-20 cm }\end{array}$} \\
\hline $\begin{array}{l}\text { Km 4-Kef } \\
\text { Kef Wenu }\end{array}$ & $\begin{array}{l}\text { Terraza fluvial/ } \\
\text { aluvial río } \\
\text { Cautín, Padre } \\
\text { Las Casas. } \\
\text { Región de la } \\
\text { Araucanía }\end{array}$ & 716.908 & 5.713 .742 & $\begin{array}{c}\text { Habitacional, } \\
\text { Mapuche } \\
\text { Histórico- } \\
\text { Colonial, siglo } \\
\text { XVI }\end{array}$ & $\begin{array}{l}\text { Fragmento de } \\
\text { pipa cerámica/ } \\
\text { boquilla (tipo } \\
\text { indeterminado) }\end{array}$ & $\mathrm{A} / \mathrm{Q}$ & Superfi & cial \\
\hline
\end{tabular}


...continuación Tabla 2.

\begin{tabular}{|c|c|c|c|c|c|c|c|}
\hline \multirow{2}{*}{ Sitio } & \multirow{2}{*}{ Emplazamiento } & \multicolumn{2}{|c|}{$\begin{array}{c}\text { Coordenadas (Datum } \\
\text { WGS 84) }\end{array}$} & \multirow{2}{*}{$\begin{array}{l}\text { Funcionalidad } \\
\text { del sitio }\end{array}$} & \multirow{2}{*}{$\begin{array}{l}\text { Descripción del } \\
\text { artefacto }\end{array}$} & \multirow{2}{*}{$\begin{array}{l}\text { Análisis } \\
\text { del } \\
\text { residuo }\end{array}$} & \multirow{2}{*}{$\begin{array}{l}\text { Procedencia intra- } \\
\text { sitio }\end{array}$} \\
\hline & & UTM este & UTM norte & & & & \\
\hline Treke II & $\begin{array}{c}\text { Litoral } \\
\text { costero área } \\
\text { de Treque, } \\
\text { Queule. } \\
\text { Región de la } \\
\text { Araucanía }\end{array}$ & - & - & No descrito & $\begin{array}{c}\text { Fragmento } \\
\text { cerámico } \\
\text { indeterminado }\end{array}$ & $\mathrm{A} / \mathrm{Q}$ & Superficial \\
\hline \multirow[b]{2}{*}{$\begin{array}{l}\text { Millahuillin } \\
1\end{array}$} & \multirow{2}{*}{$\begin{array}{l}\text { Aterrazamiento } \\
\text { en cerros } \\
\text { asociados a } \\
\text { humedales, } \\
\text { Máfil. Región } \\
\text { de los Ríos. }\end{array}$} & \multirow[b]{2}{*}{681.658} & \multirow[b]{2}{*}{5.610 .503} & $\begin{array}{c}\text { Sitio } \\
\text { habitacional } \\
\text { Alfarero Tardío } \\
\text { ¿prehispánico? } \\
\text { y cementerio } \\
\text { Colonial } \\
\text { Temprano }\end{array}$ & $\begin{array}{l}\text { Pipa cerámica: } \\
\text { acodada }\end{array}$ & $\mathrm{A} / \mathrm{Q}$ & Unidad harneo K12 \\
\hline & & & & $\begin{array}{l}\text { Cementerio } \\
\text { mapuche } \\
\text { colonial (siglos } \\
\text { XVI-XVIII) con } \\
\text { ocupación } \\
\text { doméstica- } \\
\text { ritual desde el } \\
\text { siglo XIV }\end{array}$ & $\begin{array}{l}\text { Pipa cerámica: } \\
\text { cónica directa }\end{array}$ & $\mathrm{A} / \mathrm{Q}$ & Unidad harneo $\mathrm{O} 12$ \\
\hline $\begin{array}{l}\text { Millahuillin } \\
2\end{array}$ & $\begin{array}{l}\text { Aterrazamiento } \\
\text { en cerros } \\
\text { asociados a } \\
\text { humedales, } \\
\text { Máfil. Región } \\
\text { de los Ríos. }\end{array}$ & 682.537 & 5.611 .294 & $\begin{array}{l}\text { Cementerio } \\
\text { Período } \\
\text { Colonial (siglos } \\
\text { XVII al XVIII) }\end{array}$ & $\begin{array}{l}\text { Pipa cerámica: } \\
\text { T invertida }\end{array}$ & $\mathrm{A} / \mathrm{Q}$ & Superficial \\
\hline
\end{tabular}

el caso de las $T$ invertidas que han sido recuperadas en sitios asociados a diversos períodos (Tabla 2).

El conjunto analizado en el presente estudio incluye un fragmento de pipa lítica y 11 pipas cerámicas provenientes de ocho sitios con diferentes asignaciones culturales (Tabla 2). Ningún ejemplar se encuentra completo; no obstante, en seis de ellos se pudo identificar el tipo específico de pipa, mientras que los seis restantes estaban altamente fragmentados sin posibilidad de asociarlos con uno de los tipos definidos.

Caracterización de las pipas

Pipas tipo T invertida

Este grupo se encuentra conformado por cuatro pipas cerámicas recuperadas de tres sitios (Tabla 3), y si bien todas pertenecen a un mismo tipo, es decir, poseen un hornillo central y dos tubos dispuestos en direcciones opuestas, se identificaron rasgos que las diferencian entre sí. El primero de los ejemplares, proveniente de Millahullin 2, tiene un hornillo con forma levemente cónica evertida (diámetro $24 \mathrm{~mm}$ ) y dos boquillas de forma cónica y secciones elípticas (diámetros 25 y $14 \mathrm{~mm}$ ) y es el único de este conjunto que está decorado, específicamente con engobe rojo (Fig. 2: a, b, c). Los ejemplares registrados en los sitios Lomas de Chol-Chol (Fig. 2: d, e, f) y Villa JMC-1, Labranza (Fig. 3: a, b, c) también presentan dos boquillas, pero se diferencian del caso anterior debido a que tienen dos mamelones dispuestos en la base del hornillo; este último presenta una forma cónica evertida y un diámetro de $33 \mathrm{~mm}$ (solo una de 
Tabla 3. Sitios con pipas T invertida.

\begin{tabular}{cccc}
\hline \multirow{2}{*}{ Tipo de pipa } & \multicolumn{2}{c}{ Sitio } \\
\cline { 2 - 4 } & $\begin{array}{c}\text { Villa JMC-1, } \\
\text { Labranza }\end{array}$ & Lomas de Chol-Chol & Millahuillin 2 \\
\hline T invertida & & 1 & 1 \\
\hline T invertida con mamelón perforado en la base del hornillo & 1 & \\
\hline \\
\hline
\end{tabular}

Fig. 2. a-c) pipa T invertida con decoración de engobe rojo (sitio Millahuillín 2); d-f) pipa T invertida con mamelones en la base del hornillo (sitio Lomas de Chol-Chol).
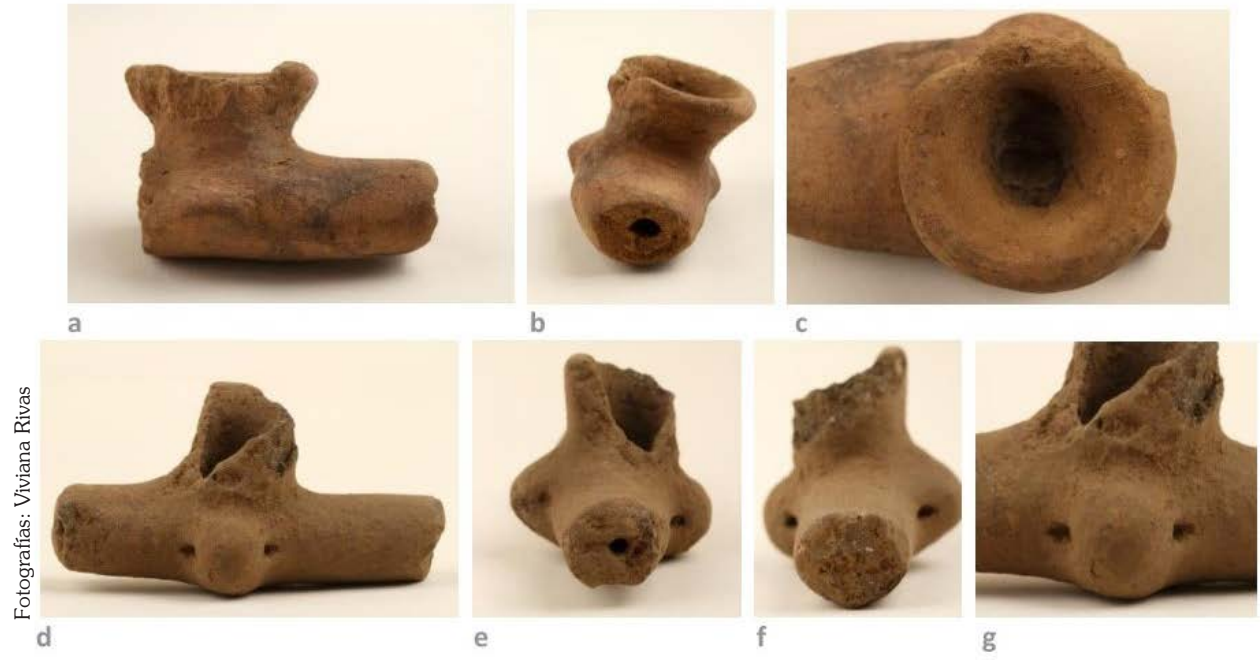

Fig. 3. a-c) pipa T invertida con mamelones en la base del hornillo (sitio Villa JMC-1, Labranza); d-g) pipa $\mathrm{T}$ invertida con mamelones perforados en la base del hornillo (sitio Villa JMC-1, Labranza).

estas pipas conservaba el hornillo), la forma de las boquillas es cónica y sus secciones circulares (diámetro $17 \mathrm{~mm}$ ) y elípticas (diámetros 17 y
$34 \mathrm{~mm})$. La cuarta pipa, también recuperada en Villa JMC-1, Labranza (Fig. 3: d, e, f), posee dos boquillas y dos mamelones perforados 
emplazados en la base del hornillo, siendo tubos rectos y de sección circular (diámetro $21 \mathrm{~mm}$ ). Todas estas pipas tienen sus superficies pulidas, $y$ debido a que se encuentran fracturadas desconocemos sus longitudes (las longitudes incompletas varían entre 39 y $79 \mathrm{~mm}$ ) pero sí pudimos consignar sus alturas, que fluctúan entre 28 y $42 \mathrm{~mm}$. Basados en la muestra aquí analizada y en las asignaciones dadas a los sitios desde donde fueron recuperadas las pipas $\mathrm{T}$ invertidas, podemos establecer que este tipo se utilizó desde el período Alfarero Temprano hasta el Colonial (Tabla 2).

Pipa tipo Acodada

Este tipo se caracteriza por poseer un hornillo dispuesto en uno de los extremos de la pipa, desde el cual se desprende una boquilla. Se recuperó un ejemplar en el sitio Millahuillín 1, aunque debido a la intervención previa no se pudo establecer una relación directa entre esta pipa y alguna tumba específica. Esta pipa cerámica, de superficie pulida, presenta un hornillo cónico evertido, el que se encuentra levemente inclinado (diámetro $21 \mathrm{~mm}$ ); la forma de su boquilla es recta y su sección subrectangular (diámetro 17 $\mathrm{mm}$ ). Debido a que está fracturada, se consignó la longitud incompleta, que es de $33 \mathrm{~mm}$, misma medida que presenta su altura (Fig 4: a, b).

\section{Pipa tipo Cónica Directa}

Ejemplar recuperado también desde el sitio Millahuillín 1. Esta pipa cerámica está conformada por una boquilla y un hornillo sin un borde que se eleve verticalmente sobre la superficie superior de la pieza; tiene un contorno continuo sin que exista diferenciación entre los sectores que la componen, presentando una forma cónica en planta y un tubo de sección circular (diámetro $17 \mathrm{~mm}$ ). Su longitud es 50 $\mathrm{mm}$ (incompleto) y su altura es $25 \mathrm{~mm}$. La superficie se encuentra pulida y decorada con círculos aplicados en toda la pipa a través de la técnica de impresión (Fig 4: c, d, e).

\section{Pipas Indeterminadas y otros}

Se registraron seis fragmentos de pipa, uno lítico y cinco cerámicos, que no pudieron ser asociados a uno de los tipos definidos (Tabla 4). Este conjunto se encuentra conformado por boquillas/tubos abiertos de forma cónica $(83,3 \%)$ o indeterminada $(16,6 \%)$ y cuyas secciones son circulares $(66,6 \%)$ o elípticas $(33,3 \%)$, las que presentan diámetros que varían entre 4,6 y $24 \mathrm{~mm}$. Las superficies de estos fragmentos son pulidas y ninguna se encuentra decorada (Fig. 5). Adicionalmente, se tuvo acceso a un fragmento de tubo recuperado en el sitio Treke 2 que,

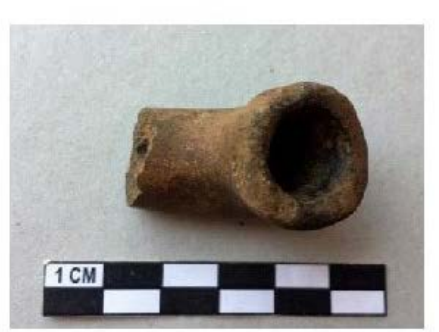

b
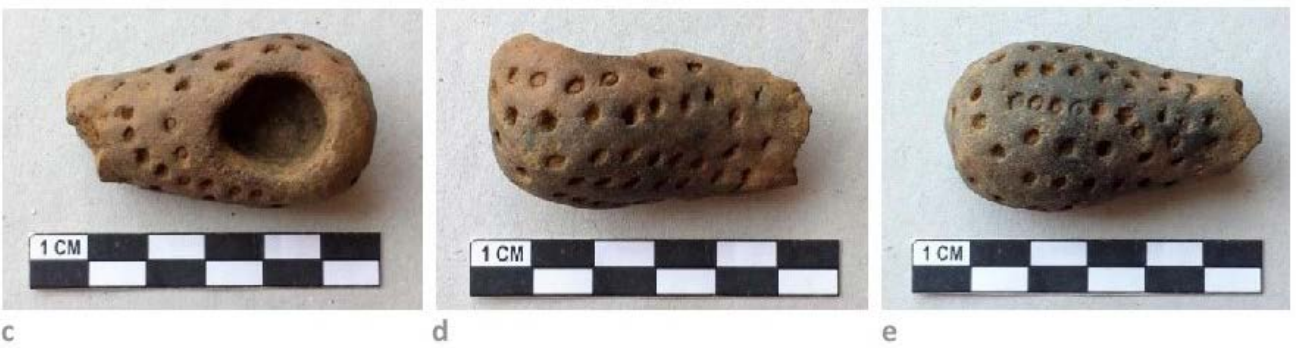

e

Fig. 4. a-b) pipa acodada (sitio Millahuillín 1); c-e) pipa cónica directa decorada con técnica de impresión (sitio Millahuillín 1). 
Tabla 4. Sitios con pipas indeterminadas.

\begin{tabular}{ccc}
\hline Sitio & Material & Sector pipa \\
\hline Parcela 31-1 & Cerámica & Boquilla \\
Km 4-Kef Kef Wenu & Cerámica & Boquilla \\
Km 0-Enlace Temuco & Cerámica & Boquilla \\
Lomas de Chol-Chol & Cerámica & Tubo abierto \\
P21-3 & Cerámica & Boquilla \\
& Lítico & Tubo abierto \\
\hline
\end{tabular}

si bien es abierto, no tiene las características morfológicas de una pipa, poseyendo una pared muy delgada $(1,7 \mathrm{~mm}$ ) y un reborde de arcilla que no coinciden con lo observado en la tipología elaborada a partir de los ejemplares completos de las colecciones (Alfaro, 2015). Sin embargo, no podemos descartar la posibilidad que haya sido una boquilla de longitud muy corta adherida a una superficie mayor de alguna pipa cuyo tipo hasta ahora desconocemos.

\section{Análisis de residuos}

La identificación de los elementos consumidos en las pipas y parafernalia asociada se basó en la evidencia química y microfósil contenida en los residuos de uso. La extracción de las muestras se realizó mediante el raspado directo en húmedo y seco de las paredes interiores de las piezas (Loy, 1994; Belmar et al. 2014). Se aplicó un protocolo de manipulación de las piezas y muestras que beneficiara su integridad, además de controlar eventos de contaminación (Belmar et al. 2014).

El análisis químico de los compuestos orgánicos presentes en los residuos carbonizados adheridos a las pipas se realizó mediante extracción solido-líquido utilizando secuencialmente cloroformo y metanol. Los extractos orgánicos obtenidos fueron sometidos a cromatografía de gases acoplada a espectrometría de masas (CGEM), tal como ha sido descrito en otros estudios (Echeverría et al. 2014; Carrasco et al. 2015; Gili et al. 2017). Para la identificación de compuestos se compararon sus índices de retención y sus espectros de masas con datos de la literatura o con estándares analíticos.

El análisis microfósil se basó en el "análisis múltiple", que prioriza la recuperación del conjunto total de microfósiles (Coil et al. 2003). La descripción de los microfósiles y sus atributos siguió el International Code for Phytolith Nomenclature 1.0 (Madella et al. 2005) y el International Code for Starch Nomesclature (ICSN, 2011), además de la propuesta de Franceschi y Horner (1980) para cristales. Se identificaron y caracterizaron los atributos relevantes de otros tipos de microfósiles (calcifitolitos, microcarbones,

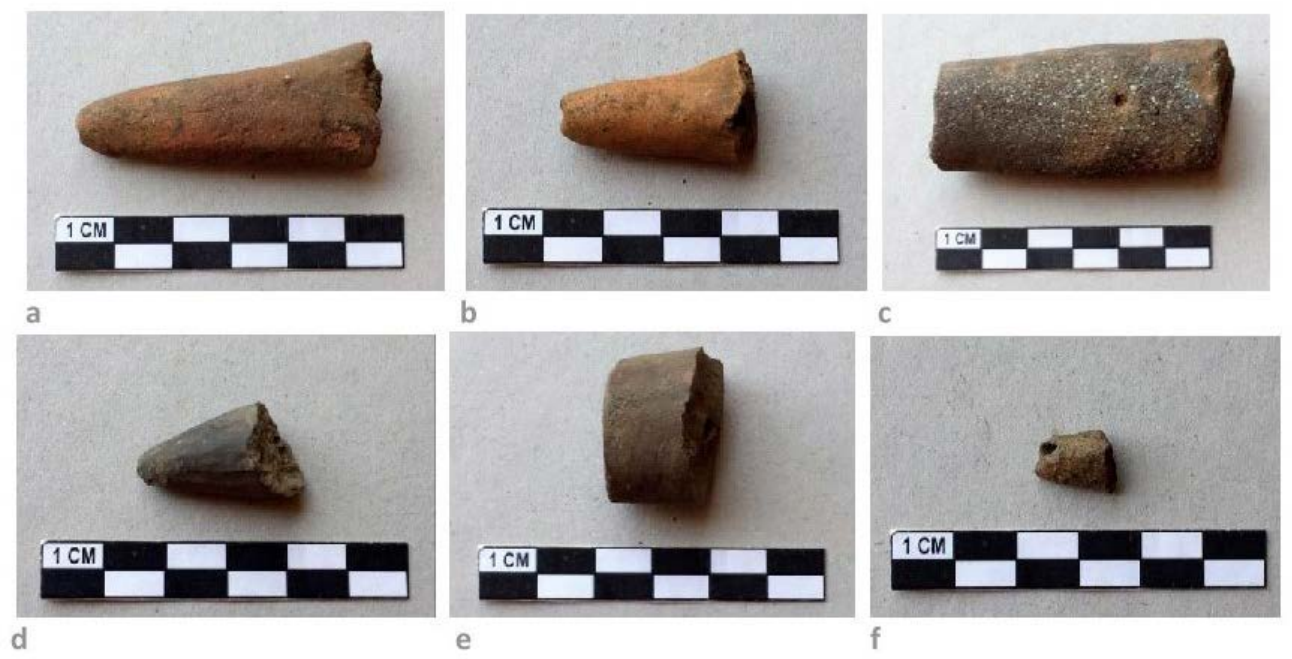

Fig. 5. a-b, d) boquillas de pipas cerámicas indeterminadas (sitios Km 0-Enlace Temuco, Km 4-Kef Kef Wenu, P21-3); c) Tubo abierto de pipa cerámica indeterminada (Lomas de Chol-Chol); e) tubo abierto de pipa lítica indeterminada (sitio P21-3); f) tubo indeterminado (sitio Treke 2). 
granos de polen, entre otros. La identificación de los microfósiles se obtuvo por comparación con aquellos obtenidos de una colección de referencia de plantas aromáticas y psicoactivas nativas de Chile/Andes centro-sur (Albornoz, 2015, 2016; Quiroz et al. 2015) y publicaciones especializadas (Korstanje \& Babot, 2007; Reichert, 1913). Las muestras se observaron bajo microscopio petrográfico con aumentos de 200x y 400x. Se registraron las modificaciones y daños detectados en los microfósiles, causados por las diferentes modalidades de procesamiento (Babot, 2007) o por posibles agentes naturales (Haslam, 2004).

\section{RESULTADOS}

\section{Análisis químico}

El análisis químico de los extractos clorofórmicos y metanólicos mostró la presencia de varios compuestos orgánicos de diversos tipos, destacándose alcoholes de cadena lineal y ramificada, metilésteres de ácidos grasos y fitoesteroles (Tabla 5). Aunque ellos no tienen un carácter diagnóstico al nivel de especie botánica, ya que se encuentran distribuidos ampliamente en el reino vegetal, los resultados evidencian el consumo de recursos vegetales en las pipas. No se observó la presencia de nicotina en el conjunto de muestras analizadas, lo que puede atribuirse a la lixiviación del alcaloide desde la pipa al medio externo y su retención en la matriz circundante, fenómeno atribuible a la proveniencia de las pipas desde los ambientes húmedos del sur de Chile. En apoyo de esta idea, el porcentaje de elementos del complejo fumatorio provenientes de Chile y que han dado análisis positivo de nicotina varía notablemente con las condiciones climáticas: $68 \%$ en pipas de sitios en los oasis de San Pedro de Atacama en el Norte Grande (Gili, 2014; Gili et al. 2017), 38\% en pipas de un sitio costero cercano a Antofagasta, también en el Norte Grande (Carrasco et al. 2015) y 39\% en objetos del complejo fumatorio del sitio La Granja, en Chile central (Belmar et al. 2016). No puede descartarse, entonces, que se haya podido fumar nicotina en las pipas del complejo Pitrén. Por otra parte, la presencia de etilésteres de ácidos grasos puede responder a la presencia de material vegetal fermentado (Saerens et al. 2008); existen evidencias etnográficas que señalan el consumo de tabaco mezclado con coadyuvantes fermentados (Wilbert, 1987). La presencia de amidas derivadas de ácidos grasos puede ser atribuida al uso de agentes de limpieza en el material arqueológico o por el efecto de guano en la matriz de suelo, que pudo haber liberado urea, la que por transformación bacteriana habría generado amoníaco (Chernysheva et al. 2015) capaz a su vez de transformar los ácidos grasos en sus amidas respectivas.

\section{Análisis de microfósiles}

Se identificó un conjunto de microfósiles tanto de origen vegetal como animal $(\mathrm{N}=166)$. Dentro de la variabilidad de microrrestos vegetales, los silicofitolitos fueron el elemento más recurrente $(\mathrm{N}=121)$, seguido de los calcifitolitos $(\mathrm{N}=16)$, granos de almidón $(\mathrm{N}=11)$ y tejidos $(\mathrm{N}=11)$, y en tres casos se advierte la presencia de microcarbones, elementos asociados directamente a la combustión. En cuanto a los microfósiles de origen animal, se registraron esferulitas en dos casos. En la Tabla 6 se detallan los microfósiles registrados por pieza, salvo las dos pipas (Isla Mocha y $\mathrm{Km}$ 0-Enlace Temuco) que no presentaron evidencia microfósil.

El conjunto de silicofitolitos, en general, presenta morfologías que permiten inferir un origen anatómico correspondiente a epidermis de tallo u hoja (Tabla 7). Estas formas serían principalmente células elongadas, buliformes y tabulares (Pearsall, 2009). Específicamente, en la pipa de Millahuillín 2 se registró un fitolito afín a Cyperaceae, además de tricomas de taxón indeterminado. En otra muestra de Millahuillín 2, la presencia de fitolitos buliformes, además de epidermis de tallo $\mathrm{u}$ hoja, permiten sugerir la presencia de hojas. Para la pieza Millahuillín 1 se identificó un conglomerado de tejidos con varios tricomas, algunos pluricelular afines a Nicotiana spp. (Fig. 6, Quiroz et al. 2015) y otros unicelulares. En la pipa de Lomas de Chol-chol se registró un silicofitolito afín a 
Tabla 5. Resultados de los análisis químicos.

\begin{tabular}{|c|c|c|}
\hline \multirow{2}{*}{ Procedencia } & \multicolumn{2}{|c|}{ Análisis químico } \\
\hline & Extracto clorofórmico & Extracto metanólico \\
\hline $\begin{array}{l}\text { Villa JMC-1, } \\
\text { Labranza, Rasgo } 23\end{array}$ & $\begin{array}{l}\text { Alcohol oleico; } n \text {-Pentadecanol; } \gamma \text {-Sitosterol; (Z)-13- } \\
\text { Docosenamida; Octadecamida; Hexadecanamida; } \\
\text { Etiléster del ácido palmítico }\end{array}$ & $\begin{array}{l}\text { Alcohol oleico; } n \text {-Pentadecanol; } \gamma \text {-Sitosterol; } \\
\text { Metilésteres de los ácidos palmítico y esteárico }\end{array}$ \\
\hline P21-3, Isla Mocha & - & - \\
\hline $\begin{array}{l}\text { P21-1/P21-2, Isla } \\
\text { Mocha }\end{array}$ & - & - \\
\hline
\end{tabular}

P 31-1, Isla Mocha, Unidad 28, Capa 1 , nivel 20-30 cm (FONDECYT 1950175)
Alcohol oleico; $n$-Pentadecanol; $n$-Nonadecanol; Metiléster del ácido palmítico; Etiléster del ácido palmítico
Alcohol oleico; $n$-Pentadecanol; $n$-Nonadecanol; $\gamma$-Sitosterol; Metilésteres de los ácidos palmítico, oleico y esteárico
Lomas de Chol-chol, Alcohol oleico; $n$-Pentadecanol; $n$-Nonadecanol; superficial
Etiléster del ácido palmítico
Alcohol oleico; $n$-Pentadecanol; $n$-Nonadecanol; Metilésteres de los ácidos palmítico, oleico y esteárico
Lomas de Chol-chol, Alcohol oleico; $n$-Pentadecanol; $n$-Nonadecanol: superficial
$\gamma$-Sitosterol; Etiléster del ácido palmítico
Alcohol oleico; $n$-Pentadecanol; $n$-Nonadecanol: Metilésteres de los ácidos palmítico, oleico y esteárico
Padre Las Casas, Km Alcohol oleico; $n$-Pentadecanol; $n$-Nonadecanol; $\gamma$ - y 0-Enlace Cajón, By $\quad \beta$-Sitosterol; Etiléster del ácido palmítico pass Temuco, Unidad $\mathrm{J} 13,0-20 \mathrm{~cm}$
Alcohol oleico; $n$-Pentadecanol; $n$-Nonadecanol; Metiléster del ácido palmítico
Ken 4, Kef Kef Wenu, Alcohol oleico; $n$-Pentadecanol; $n$-Nonadecanol; Superficial (Temuco) $\quad \gamma$-Sitosterol; Etiléster del ácido palmítico
Alcohol oleico; $n$-Pentadecanol; $n$-Nonadecanol; Metilésteres de los ácidos palmítico, oleico y esteárico
Treke II, Unidad 23, Recolección superficial K12

\section{Alcohol oleico; $n$-Pentadecanol; $n$-Nonadecanol;} Etiléster del ácido palmítico
Millahuillin 1, Unidad
Alcohol oleico; $n$-Pentadecanol; $n$-Nonadecanol; Metiléster del ácido palmítico; $\gamma$-Sitosterol
Alcohol oleico; $n$-Pentadecanol; (E)-9-Octadecen-1ol; $n$-Nonadecanol-1; Hexatriacontano; $\gamma$-Sitosterol; Etiléster del ácido palmítico
Alcohol oleico; $n$-Pentadecanol; $n$-Nonadecanol; Metilésteres de los ácidos palmítico, oleico y esteárico; Fitol
Alcohol oleico; $n$-Pentadecanol; $n$-Nonadecanol; Millahuillin 1, Unidad Pentadecanal; $\gamma$-Sitosterol; Etiléster del ácido palmítico $\mathrm{O} 12$
Alcohol oleico; $n$-Pentadecanol; $n$-Nonadecanol; Metilésteres de los ácidos palmítico, oleico, esteárico y behénico
Alcohol oleico; $n$-Pentadecanol; $n$-Nonadecanol; (Z,Z)-

Muillahuillin 2 9,12-octadecadien-1-ol; 1-Hentetracontanol; Etiléster del ácido palmítico
Alcohol oleico; $n$-Pentadecanol; $n$-Nonadecanol; Metilésteres de los ácidos palmítico, oleico y esteárico
Cyperaceae; además, se reconocen fitolitos de hojas y epidermis de tallos y hojas al interior del hornillo de la pieza.

Por otra parte, las modificaciones físicoquímicas de los microfósiles también son útiles como indicadores de modos de procesar plantas (Babot, 2007; Belmar et al. 2016). Las marcas registradas en estos microvestigios son señal de procesos de molienda y quemado, específicamente se detectó la termoalternación de tejidos silicificados. También se registraron deterioros en los granos de almidón, tales como 
Tabla 6. Presencia de microfósiles por pieza.

\begin{tabular}{|c|c|c|c|}
\hline Sitio & Artefacto & Tipo microfósil y cantidad & Total \\
\hline \multirow{3}{*}{ Villa JMC-1, Labranza } & \multirow{3}{*}{ Jarro (pichimetawe) de seis bocas } & Silicofitolitos $(\mathrm{N}=7)$ & \multirow{3}{*}{15} \\
\hline & & Tejidos $(\mathrm{N}=8)$ & \\
\hline & & Microcarbones & \\
\hline \multirow{3}{*}{$P 21-3$} & \multirow{3}{*}{ Fragmento de pipa lítica } & $\begin{array}{l}\text { Grano de almidón }(\mathrm{N}=2) \\
\text { Paquete almidones }(\mathrm{N}=1)\end{array}$ & \multirow{3}{*}{12} \\
\hline & & Silicofitolito $(\mathrm{N}=9)$ & \\
\hline & & Cuerpo de lípidos & \\
\hline \multirow{6}{*}{ Lomas de Chol-Chol } & \multirow{3}{*}{ Fragmento de pipa cerámica } & Grano de almidón $(\mathrm{N}=1)$ & \multirow{3}{*}{4} \\
\hline & & Silicofitolito $(\mathrm{N}=2)$ & \\
\hline & & Esferulita $(\mathrm{N}=1)$ & \\
\hline & \multirow{2}{*}{ Fragmento de pipa cerámica } & Silicofitolito $(\mathrm{N}=2)$ & \multirow{2}{*}{3} \\
\hline & & Tejido $(\mathrm{N}=1)$ & \\
\hline & Fragmento de pipa cerámica & Silicofitolito $(\mathrm{N}=38)$ & 38 \\
\hline Km 0-Enlace Temuco & Fragmento de pipa cerámica & No se registran & - \\
\hline \multirow{2}{*}{ Km 4-Kef Kef Wenu } & \multirow{2}{*}{ Fragmento de pipa cerámica } & Grano de almidón (N=2) & \multirow{2}{*}{4} \\
\hline & & Silicofitolitos $(\mathrm{N}=2)$ & \\
\hline \multirow{3}{*}{ Treke II } & \multirow{3}{*}{ Fragmento de cerámico indefindo } & Grano de almidón $(\mathrm{N}=3)$ & \multirow{3}{*}{21} \\
\hline & & Silicofitolitos $(\mathrm{N}=2)$ & \\
\hline & & Calcifitolitos $(\mathrm{N}=16)$ & \\
\hline \multirow{7}{*}{ Millahuillín 1} & \multirow{2}{*}{ Fragmento de pipa } & Grano de almidón $(\mathrm{N}=4)$ & \multirow{2}{*}{7} \\
\hline & & Silicofitolito $(\mathrm{N}=3)$ & \\
\hline & \multirow{4}{*}{ Fragmento de pipa } & Grano de almidón $(\mathrm{N}=1)$ & \multirow{4}{*}{3} \\
\hline & & Tejido $(\mathrm{N}=1)$ & \\
\hline & & Esferulita $(\mathrm{N}=1)$ & \\
\hline & & Microcarbones & \\
\hline & Fragmento de pipa & Silicofitolitos $(\mathrm{N}=2)$ & 2 \\
\hline \multirow{5}{*}{ Millahuillín 2} & \multirow{5}{*}{ Fragmento de pipa } & Grano de almidón $(\mathrm{N}=1)$ & \multirow{5}{*}{69} \\
\hline & & Silicofitolitos $(\mathrm{N}=63)$ & \\
\hline & & Calcifitolitos $(\mathrm{N}=4)$ & \\
\hline & & Tejido $(\mathrm{N}=1)$ & \\
\hline & & Microcarbones & \\
\hline P31-1 & Fragmento de pipa & No se registró material & 0 \\
\hline \multicolumn{3}{|c|}{ Total } & 166 \\
\hline
\end{tabular}

el hilo dañado y bajo brillo o ausencia de éste, gelatinización, hilo perforado, cruz engrosada, pérdida birrefringencia y de contorno. La presencia de arenas cristalinas conglomeradas y fractura de tricomas son más indicadores relacionados con modos de procesamiento. Esto se ve reforzado por la presencia de microcarbones en el jarro (pichimetawe) y en los hornillos de una pipa de Millahuillín 2 y Lomas de Chol-Chol, situación que confirma el uso del jarro como elemento asociado a la quema o la generación de humo y la utilización de los hornillos de las pipas.

Por último, la presencia de esferulitas en 
Tabla 7. Microfósiles identificados según partes o afinidad taxonómica por pieza.

\begin{tabular}{|c|c|c|c|c|c|}
\hline Artefacto & Tipo Microfósil & Origen Anatómico & $\begin{array}{l}\text { Afinidad } \\
\text { Taxonómica }\end{array}$ & Daños & Referencia \\
\hline \multirow{3}{*}{$\begin{array}{l}\text { Villa JMC-1, } \\
\text { Labranza } \\
\text { Jarro } \\
\text { (pichimetawe) } \\
\text { de seis bocas }\end{array}$} & Silicofitolitos $(\mathrm{N}=7)$ & $\begin{array}{l}\text { Epidermis de tallo y } \\
\text { hoja }\end{array}$ & & Coloración marrón & $\begin{array}{l}\text { Piperno, 2006; } \\
\text { Pearsall, } 2009\end{array}$ \\
\hline & Tejidos $(\mathrm{N}=8)$ & $\begin{array}{l}\text { Tricoma pluricelular/ } \\
\text { Células esféricas con } \\
\text { paredes enriquecidas en } \\
\text { celulosa }\end{array}$ & & Coloración marrón & \\
\hline & Microcarbones & & & & \\
\hline \multirow{4}{*}{$P 21-3$} & $\begin{array}{l}\text { Granos de almidón } \\
(\mathrm{N}=2)\end{array}$ & & & Bajo brillo & \\
\hline & $\begin{array}{l}\text { Paquete de } \\
\text { almidones }(\mathrm{N}=1)\end{array}$ & & & & \\
\hline & Silicofitolitos $(\mathrm{N}=9)$ & & & & \\
\hline & Cuerpo de lípidos & & & & \\
\hline \multirow{3}{*}{$\begin{array}{l}\text { Lomas de } \\
\text { Chol-Chol }\end{array}$} & $\begin{array}{l}\text { Grano de almidón } \\
(\mathrm{N}=1)\end{array}$ & & & & \\
\hline & Silicofitolito $(\mathrm{N}=2)$ & Tejido de conducción & & & $\begin{array}{l}\text { Piperno, 2006; } \\
\text { Pearsall, } 2009\end{array}$ \\
\hline & Esferulita $(\mathrm{N}=1)$ & & & & \\
\hline \multirow{2}{*}{$\begin{array}{l}\text { Lomas de } \\
\text { Chol-Chol }\end{array}$} & Silicofitolito $(\mathrm{N}=2)$ & & & & \\
\hline & Tejido $(\mathrm{N}=1)$ & Tejido de conducción & & & $\begin{array}{l}\text { Piperno, 2006; } \\
\text { Pearsall, } 2009\end{array}$ \\
\hline \multirow{2}{*}{$\begin{array}{l}\text { Lomas de } \\
\text { Chol-Chol }\end{array}$} & $\begin{array}{l}\text { Silicofitolitos } \\
(\mathrm{N}=38)\end{array}$ & $\begin{array}{l}\text { Epidermis de tallo y } \\
\text { hoja }\end{array}$ & Cyperaceae & & $\begin{array}{l}\text { Piperno, 2006; } \\
\text { Pearsall, } 2009\end{array}$ \\
\hline & Microcarbones & & & & \\
\hline \multirow{2}{*}{$\begin{array}{c}\text { Km 4-Kef Kef } \\
\text { Wenu }\end{array}$} & $\begin{array}{l}\text { Grano de almidón } \\
(\mathrm{N}=2)\end{array}$ & - & & $\begin{array}{l}\text { Perdida de brillo y } \\
\text { birrefringencia }\end{array}$ & \\
\hline & Silicofitolitos $(\mathrm{N}=2)$ & $\begin{array}{l}\text { Epidermis de tallo y } \\
\text { hoja }\end{array}$ & & & $\begin{array}{l}\text { Piperno, 2006; } \\
\text { Pearsall, } 2009\end{array}$ \\
\hline \multirow{3}{*}{ Treke II } & $\begin{array}{l}\text { Grano de almidón } \\
(\mathrm{N}=3)\end{array}$ & Hojas, tallos y frutos & $\begin{array}{l}\text { Cf. Tallo Latua } \\
\text { pubiflora }\end{array}$ & Pérdida de la forma & Albornoz, 2016 \\
\hline & Silicofitolitos $(\mathrm{N}=2)$ & & & & \\
\hline & $\begin{array}{l}\text { Calcifitolitos } \\
(\mathrm{N}=16)\end{array}$ & Tallo y hojas & $\begin{array}{l}\text { Cf. Tallo Latua } \\
\text { pubiflora }\end{array}$ & & Albornoz, 2016 \\
\hline Millahuillín 1 & Silicofitolito $(\mathrm{N}=2)$ & Hoja & & & $\begin{array}{l}\text { Piperno, 2006; } \\
\text { Pearsall, } 2009\end{array}$ \\
\hline \multirow{2}{*}{ Millahuillín 1} & $\begin{array}{l}\text { Grano de almidón } \\
(\mathrm{N}=4)\end{array}$ & Hojas, tallos y frutos & & & \\
\hline & $\begin{array}{l}\text { Silicofitolitos } \\
(\mathrm{N}=3)\end{array}$ & $\begin{array}{l}\text { Epidermis de tallo y } \\
\text { hoja }\end{array}$ & & & $\begin{array}{l}\text { Piperno, 2006; } \\
\text { Pearsall, } 2009\end{array}$ \\
\hline \multirow{3}{*}{ Millahuillín 1} & $\begin{array}{l}\text { Grano de almidón } \\
(\mathrm{N}=1)\end{array}$ & & & & \\
\hline & Tejido $(\mathrm{N}=1)$ & $\begin{array}{l}\text { Epidermis de hoja } \\
\text { con tricomas uni y } \\
\text { pluricelulares }\end{array}$ & Afín Nicotiana spp. & & Quiroz et al. 2015 \\
\hline & Esferulita $(\mathrm{N}=1)$ & & & & \\
\hline
\end{tabular}


...continuación Tabla 7.

\begin{tabular}{|c|c|c|c|c|c|}
\hline Artefacto & Tipo Microfósil & Origen Anatómico & $\begin{array}{c}\text { Afinidad } \\
\text { Taxonómica }\end{array}$ & Daños & Referencia \\
\hline \multirow{5}{*}{ Millahuillin 2} & $\begin{array}{l}\text { Grano de almidón } \\
(\mathrm{N}=1)\end{array}$ & & & & \\
\hline & $\begin{array}{l}\text { Silicofitolitos } \\
(\mathrm{N}=63)\end{array}$ & $\begin{array}{l}\text { Epidermis de tallo y } \\
\text { hoja/Tricoma }\end{array}$ & Cyperaceae & & $\begin{array}{l}\text { Piperno, 2006; } \\
\text { Pearsall, } 2009\end{array}$ \\
\hline & Calcifitolitos $(\mathrm{N}=4)$ & Tallo & & & \\
\hline & Tejido (N=1) & & & & \\
\hline & Microcarbones & & & & \\
\hline
\end{tabular}

las piezas de Lomas de Chol-Chol y Millahuillín 1 puede indicar el uso de bosta como catalizador del efecto psicoactivo (Guevara, 1911; Guevara \& Oyarzún, 1912; Serrano, 1934).

En el fragmento cerámico no determinado del sitio Treke II se recuperó un paquete de almidones y calcifitolitos asignable a cf. Latua pubiflora (latué) (Albornoz, 2016) (Fig. 7).

\section{DISCUSIÓN}

Se ha documentado ampliamente la práctica de fumar entre los grupos mapuches (Planella et al. 2012, Planella et al. 2016). Se han constatado los primeros indicios materiales de esta actividad para el período Alfarero Temprano (Complejo Pitrén) en la forma de pipas cerámicas y líticas de doble boquilla en forma $\mathrm{T}$ invertidas tanto en sitios de la vertiente occidental como oriental de los Andes (área de Neuquén), asociadas tanto a contextos funerarios como habitacionales (Aldunate, 1989; Westfall, 1993-1994).

Si bien las pipas forman parte del contexto artefactual vinculado al Complejo Fumatorio, son pocos los sitios con fechas y asociaciones contextuales claras. Se conocen los antecedentes de los sitios El Alero Cabeza de Indio 1, emplazado en los faldeos orientales del volcán Llaima (1830 \pm 40 años AP, $1100 \pm 40$ años AP y $670 \pm 40$ años AP; Adán, 2009); Montículo de Angostura (1050 DC), ubicado entre los lagos Aluminé y Moquehue (Aldunate, 1989); Km 15-Lof Mahuida, cerca del cerro Conhueno $(830 \pm 135$ años AP, Ocampo et al. 2004), y Cueva de los Catalanes, en el área de Mininco, donde se registra la presencia de dos pipas en el componente adscrito al mismo complejo (Menghin, 1962; Berdichewsky, 1968).

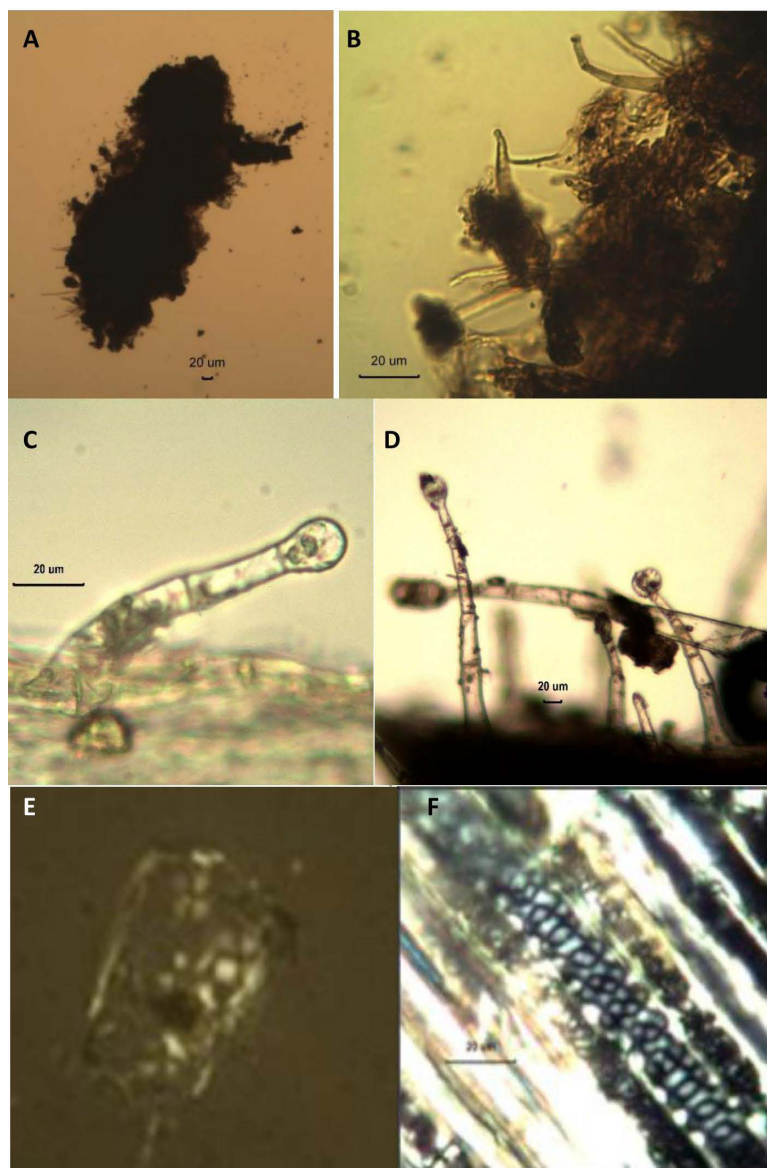

Fig. 6. A) Conglomerado de tejido con tricomas, aff. Nicotiana sp.; B) detalle de tricomas glandular pluricelular, aff. Nicotiana sp.; C) Tricoma glandular pluricelular uniseriado, flor de Nicotiana corymbosa (Quiroz 2014); D) Tricoma glandular pluricelular uniseriado, botón floral de Nicotiana miersii (Quiroz 2014); E) Paquete con almidones, cf. Latua pubiflora F) Fibra con almidones Latua pubiflora (Albornoz 2016). 

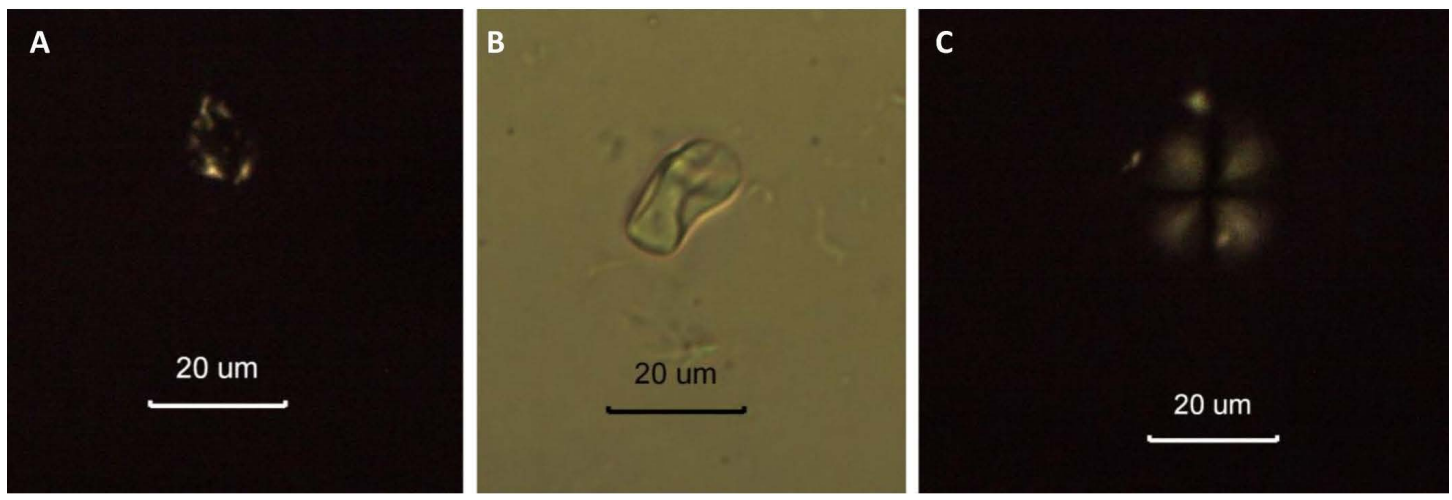

Fig. 7. Almidones con daños por procesamiento.

La tradición perdura en el tiempo, continuando hacia momentos más tardíos asignables al Complejo Vergel; no obstante, se reitera el mismo problema pesquisado para los contextos del complejo Pitrén, es decir que muchas piezas se encuentran sin contextos claros o corresponden a hallazgos aislados (Aldunate, 1989; Westfall, 1993-1994).

Según algunos estudios, se logran delimitar áreas donde hay una concentración de estas evidencias; una de ellas es en las cercanías de Angol, donde se describen pipas tanto de piedra como de cerámica (Wetsfall, 1993-1994). El registro mostraría una mayor concentración de pipas en ambas vertientes de la cordillera de Nahuelbuta, principalmente en un área que incluye Purén, Contulmo, Lanalhue, Cañete, Paicaví, Antiquina, Quidico y Tirúa (Joseph, 1930; Westfall 1993-1994). Otra área rica en pipas es Contulmo, que se caracteriza por las pipas "comunales", las cuales tienen una forma estrellada y con más de dos boquillas, usualmente elaboradas en piedra. Se ha propuesto que las boquillas cortas de estas pipas posiblemente constituyan orificios en los cuales se insertaban tubos de aspiración hechos de madera o caña (Westfall 1993-1994). Asimismo, hay registros de cachimbas de tres, cuatro, cinco, seis y aún una con doce aperturas, provenientes de Arauco (Bullock, 1944) y pipas con prolongaciones cefaloides en la zona de Contulmo (Joseph 1930).

En términos generales, los antecedentes señalan la presencia de pipas desde el período Alfarero Temprano hasta el Histórico;

5 La tipología fue realizada integrando tanto las pipas con contexto como las provenientes de colecciones, la mayoría de las cuales no contaban con datos contextuales. Además, lamentablemente, la mayoría de las pipas del área sur están descontextualizadas, por lo que no se pueden establecer asociaciones de sus rasgos tecnológicos con variables temporales, espaciales o culturales. Si bien el presente artículo se centró en una muestra compuesta por 12 pipas contextualizadas (11 cerámicas y una lítica), complementariamente el trabajo realizado a partir de las colecciones nos permitió acceder a un número importante de pipas cerámicas $(\mathrm{N}=86)$ que, pese a estar descontextualizadas, sirvieron de referencia para poder compararlas con las que sí contaban con su procedencia. Producto del análisis, se observó una significativa variabilidad morfológica, la que fue sistematizada a través de una tipología elaborada solo con los ejemplares cerámicos ( $\mathrm{N}=97)$, razón por la cual le reconocemos su carácter de preliminar debido a que no abarcó la totalidad de las pipas disponibles en el sur de Chile ni tampoco las manufacturadas con otras materialidades. La tipología ${ }^{5}$ incluyó tipos ya conocidos y otros que fueron definidos por nosotros, correspondiendo a T invertida $(\mathrm{N}=16)$, con extensión ciega $(\mathrm{N}=14)$, acodada ( $\mathrm{N}=12)$, redonda con boquilla extendida $(\mathrm{N}=6)$, vertical $(\mathrm{N}=2)$, cónica directa $(\mathrm{N}=2)$, redonda con hornillo central $(\mathrm{N}=1)$, indeterminadas $(\mathrm{N}=36)$ y ocho pipas que aún están en proceso de análisis.

Enfocándonos en las muestras con contexto, se trata de un grupo poco numeroso proveniente de ocho sitios con asignaciones culturales que cubren desde el período Alfarero Temprano hasta el Histórico, siendo seis de los ejemplares 
asociados con uno de los tipos señalados ( $T$ invertida, acodada y cónica directa), mientras que los seis restantes corresponden a fragmentos de tubos abiertos y boquillas en los que no fue factible identificar las piezas originales de las que eran parte. No logramos detectar similitudes o variaciones temporales y/o espaciales entre los tipos analizados, estableciéndose solo para el caso de las T invertidas la existencia de una continuidad temporal en su uso, tal como lo confirman las asignaciones dadas a los sitios desde donde fueron recuperadas (período Alfarero Temprano en Villa JMC-1, Labranza, Alfarero Tardío en Lomas de Chol-Chol y Colonial en Millahuillín 2). La pipa $T$ invertida es una de las más frecuentes. Predomina el uso de dos boquillas por sobre la opción de una boquilla junto a un tubo ciego; este último rasgo fue observado únicamente en una pipa existente en el Museo Mapuche de Cañete. La aplicación de mamelones en la base del hornillo es otra característica de las $\mathrm{T}$ invertidas; el $50 \%$ del total contabilizado los presenta, siendo el ejemplar recuperado en Millahuillín 2, del conjunto con contexto, el único que no tiene este rasgo morfológico. La utilización de decoración es muy poco usual, registrándose este atributo en la $\mathrm{T}$ invertida recuperada en Millahuillín 2 (rojo engobado) y en una analizada en el Museo Regional de la Araucanía (decoración del tipo acanalada).

Las pipas acodada y cónica directa fueron recuperadas en el sitio Millahuillín 1 pero en sectores asociados a períodos distintos. Las pipas acodadas no tienen diferencias notorias en su morfología, específicamente la recuperada en el sitio mencionado es monocroma, mientras que de las pertenecientes a colecciones cuatro tienen decoración, identificándose diversas técnicas: engobe, modelado zoomorfo, inciso lineal, combinación de engobe junto a inciso anular y decoración en relieve. La pipa cónica directa es un tipo poco numeroso. También es poco frecuente la técnica decorativa de impresión que presentaba el ejemplar encontrado en Millahuillín 1 y que también se registró en una pieza proveniente del Museo Regional de la Araucanía y en otras descritas por Ortiz (1968), aunque en todos esos casos la decoración fue aplicada sobre otros tipos de pipas.
$\mathrm{Si}$ bien los análisis químicos señalan la presencia de una serie de compuestos orgánicos que evidencian el consumo de plantas en las pipas, se logró determinar una afinidad taxonómica a través de la evidencia microfósil en algunas pipas. Por una parte, se reconoce la presencia de Cyperaceae en una pieza de Lomas de Chol-Chol y de Millahuillín 2; posiblemente indicando actividades de limpieza de las pipas con tallos o el uso de partes de esta planta en encender la pipa (Guevara, 1911; Quiroz et al. 2012) Por otra parte, el tejido con rasgos de epidermis de hoja con tricomas uni y pluricelulares hallado en una pipa de Millahuillín 1 indica la presencia de microrrestos afín a Nicotiana spp., taxón que también se identificó en las pipas de Villa JMC 1-Labranza (Quiroz et al. 2012), lo cual reitera la asociación del tabaco nativo al complejo fumatorio. En este último sitio, las pipas contenían Poaceae, relacionado al prendido de la pipa y Solanaceae y Solanum sp., la que corresponden a especies que también pueden ser fumadas, en reemplazo del tabaco (Serrano, 1934; Housse, 1940; Quiroz et al. 2012).

También se constató la presencia de morfotipos de hoja en las dos piezas de Millahuillín 1; de hojas, tallo o frutos en la pieza indeterminada de Treke II y Millahuillín 1 (paquete de almidones); y epidermis de hoja o tallo en las piezas de Km 4-Kef Kef Wenu y Millahuillín 1. En relación a esta evidencia, está ampliamente documentado el consumo de hojas de diversas plantas para fumar, además de poder ir incluidos los tallos de las hojas por accidente (Núñez de Pineda \& Bascuñán, 1863[1637]; Rosales, 1877-1878; Medina, 1898; Serrano, 1934; Guevara, 1911; Guevara \& Oyarzún, 1912; Joseph, 1931; Latcham, 1936; Housse, 1940; Cooper 1949; Falkner, 1774; Hilger, 1957; Möesbach, 1992[1959]; Molina, 2000[1788]). También se conoce el uso de frutos para aromatizar (Cooper, 1949; Martinic, 1991). Los antecedentes etnográficos y etnohistóricos sobre las especies incorporadas a las prácticas fumatorias mencionan ocho especies de Nicotiana, corteza de maqui (Aristotelia chilensis) y bosta de caballo (Guevara \& Oyarzún, 1912). Además, se menciona el consumo de hojas de la papa silvestre, del molle, la planta del maqui, la pitra...La madera del maqui la 
desmenuzan hoy y la mezclan al tabaco para aromatizarlo (Serrano, 1934, pp. 416-418.); en ese sentido, queda bastante por investigar sobre los Complejos Fumatorios de la zona centro sur. Esto significa ampliar la muestra de piezas con contextos para tener un panorama más extenso de los contextos de uso de las pipas, además de seguir ampliando la colección de referencia para detectar más plantas incorporadas a las pipas.

También es interesante resaltar que al referirnos al Complejo Pitrén y los relatos etnográficos relacionados, atraen la atención las numerosas menciones a la Pitra o pichra (Myrceugenia pitra) como planta aromatizante utilizada en las pipas, así como las acepciones de la palabra pütrem como toda sustancia fumable; de pütremen o pütremtun como acto de absorber el humo, de quemar algo que echa humo (Guevara, 1911) o como el acto de fumar (Guevara \& Oyarzún, 1912); de püchrem como el tabaco (Augusta, 1916; Serrano, 1934); de pütremtuve como el fumador (Erize, 1987); y de pëtremtufi ñi cutran (Möesbach 1992 [1959]) al envolver la machi con humo de tabaco al enfermo durante un machitun. Es decir, hay un conjunto de significantes y significados semánticos vinculados a dicha especie, al uso de la pipa y al humo que podrían haber incidido en el origen de la denominación de Pitrén y que continúa en el área, ciertamente con variaciones, hasta tiempos históricos.

Otro aspecto interesante de destacar es la reiteración del uso del tabaco en contextos del norte semiárido, zona central y centro-sur. Esto habla del consumo compartido del tabaco pues se encuentra en pipas procedentes de varias regiones geográficas (norte semiárido, zona central y centro-sur) durante el período Alfarero Temprano, además de la prolongación de una tradición de consumirlo desde el PAT hasta tiempos históricos, avalado por la presencia de Nicotiana spp. en pipas de la zona centro-sur, específicamente en el sitio Millahuillín 2, cementerio mapuche histórico temprano, sumado a las referencias etnográficas ya citadas.

Por otra parte, se refrenda el consumo del latué (Latua pubiflora) en el fragmento cerámico indefinido en el sitio Treke II. Esta planta constituye parte de la flora de la región, específicamente en las zonas costeras. En general, se relata la elaboración de infusiones con latué; sin embargo, existe una mención que señala que se fumaba (Plowman et al. 1971). Sin duda su alta toxicidad es conocida, señalándose su poder distintivo y peligroso (Quiróz \& Olivares, 1987; Plowman et al. 1971). Posee la capacidad de comunicación con el otro mundo, considerándose una planta de machis (Plowman et al. 1971). Es interesante que este hallazgo no corresponda a una pipa sino a un fragmento indefinido, posiblemente refrendando su consumo como infusión más que como un elemento para fumar.

Según este estudio preliminar, no se logró constatar una relación entre tipos de pipas y lo que se fumó, por lo que es necesario seguir analizando más piezas para ver si existe tal correlación.

Otro aspecto a resaltar se refiere al modo de uso de las pipas $\mathrm{T}$ invertida con ambos tubos/boquillas abiertos, tipo de artefacto que compartieron los grupos del centro y centro-sur durante el período Alfarero Temprano. Latcham (1924, p. 450) describe su uso en tiempos históricos con la participación de dos actores, el machi aspirando por un extremo mientras que un ayudante soplaba por el otro, logrando con ello obtener más rápidamente el efecto buscado, al entrar también el humo por las narices.

Finalmente, el análisis del jarro (pichimetawe) de seis bocas de Villa JMC-1, Labranza arrojó la presencia de tejidos con evidencia de termoalteración y microcarbones, lo cual apunta a la quema de plantas en el contenedor, posiblemente con la finalidad de generar humo. No se logró determinar una afinidad taxonómica; sin embargo, la presencia de células largas se puede relacionar con la quema de epidermis de tallo u hoja (Núñez de Pineda \& Bascuñán, 1863[1637]; Rosales, 1877-1878; Medina, 1898; Guevara, 1911; Métraux, 1942; Cooper, 1949; Faron, 1964; Dowling, 1971; Föerster, 1985; Wilbert, 1987; Föerster, 1995; Föerster \& Gundermann, 1996; Molina, 2000 [1788]). Este resultado, sumado al análisis de residuos de las pipas y los datos documentales mencionados, ilustra la importancia del humo y el contexto de uso ritual de las pipas en la zona centro-sur. Sin duda, estos aspectos se sugieren o se visualizan con la ayuda de los datos disponibles; 
muchos otros serán incorporados a medida que sea posible incrementar las investigaciones en la compleja región centro-sur.

\section{CONCLUSIONES}

Las pipas han actuado como un indicador relevante en la caracterización de unidades culturales de la zona centro-sur de Chile; sin embargo, en la tarea de estudiar los contextos depositados en los museos de la región se percibió el vacío de información relativo a la procedencia de las piezas. En ese sentido, al no contar con contextos definidos difícilmente se pueden realizar mayores inferencias sobre el Complejo Fumatorio en la zona. No obstante, en este primer acercamiento se logró trabajar con un conjunto de 12 pipas que representan contextos desde el PAT hasta momentos históricos. A partir de este conjunto se constata la continuidad del uso de las pipas $\mathrm{T}$ invertidas y del consumo de Nicotiana spp. en cuatro áreas geográficas, norte grande y semiárido, zona central y centro-sur, durante el período Alfarero Temprano. Los estudios de los contextos de la zona centro-sur amplían la continuidad del uso de estos dos elementos en el tiempo, extendiéndose hacia momentos históricos. Además, se logra definir la presencia de siete tipos morfológicos de pipas, lo cual refleja la variedad de formas que lo distingue de las otras áreas.

Los relatos documentales sostienen la importancia de esta práctica realzando su valor en la generación del humo y su participación de diversas ceremonias. Surge la necesidad de ahondar más en este problema aprovechando su valor diacrónico en esta área, ampliando la muestra hacia contextos claros en los que sí se puedan definir las continuidades y cambios relacionados con las prácticas fumatorias.

\section{AGRADECIMIENTOS}

Este trabajo fue desarrollado en el marco de los proyectos FONDECYT 1121097 "Los Complejos Fumatorios del Período Alfarero Temprano en Chile semiárido y centro-sur: un estudio multidisciplinario", FONDECYT 1130730 "Arqueología histórica de la ciudad de Valdivia y su jurisdicción en el período colonial" y FONDECYT 1171735 "Transformaciones e interacción en la Plaza Presidio de Valdivia durante el siglo XVIII: asentamientos, redes y circulación de materialidades". Queremos agradecer especialmente a Simón Urbina, encargado del Laboratorio de Arqueología de la Dirección Museológica de la Universidad Austral de Chile; a Miguel Chapanoff y María José Rodríguez, del Museo Regional de la Araucanía, por su gran ayuda y apoyo, y a Juana Paillalef y Patricia Muñoz, del Museo Mapuche de Cañete, por su valiosa colaboración y ayuda. A José Castelleti, Susana Nahoe y Pablo González por su trabajo en el sitio Lomas de Chol-Chol; a Elizabeth Matisoo-Smith, Andrea Seelenfreund y José Miguel Ramírez, responsable e investigadores respectivamente del proyecto "Redrawing the Polynesian triangle" financiado por Marsden Fund, The Royal Society of New Zealand; y a Carlos Ocampo y Pilar Rivas, responsables de los rescates arqueológicos en el By Pass Temuco (Ciprés consultores Ltda.). Finalmente, deseamos agradecer a los evaluadores, cuyos comentarios contribuyeron a mejorar el artículo.

\section{BIBLIOGRAFÍA}

Adán, L. (2000). Sistematización de la alfarería del complejo Pitrén. Descripción de la metodología empleada. Contribución arqueológica, 5(I), 225-241.

Adán, L. (2009). Informe final proyecto Fondecyt regular 1060216. Habitando bosques, lagos y volcanes: comparación de las ocupaciones Arcaico y Alfarero Temprano en los ámbitos cordilleranos Lla1ma Lonquimay Villarica-Lanin (39S). Santiago: Conicyt. Consultado en diciembre 2015.

Adán, L. (2012). Informe de visita a terreno, predio Pampa Gorda de Forestal Valdivia SA, sector Millahuillín, comuna de Máfil, región de Los Ríos. Valdivia. Centro de Documentación del Consejo de Monumentos Nacionales. Manuscrito.

Adán, L. (2014). Los Reche-Mapuche a través de su sistema de asentamiento (S. XV - XVII). (Tesis doctoral para optar al grado de Doctora en Historia Mención Etnohistoria). Facultad de Filosofía y Humanidades, Escuela de Postgrado, Departamento de Ciencias Históricas, Universidad de Chile.

Albornoz, X. (2015). Colección de referencia de microrrestos vegetales: especies psicoactivas y aromáticas de los 
Andes centro-sur. En Belmar, C., \& Lema, V. (Eds), Avances y desafíos metodológicos en arqueobotánica: miradas consensuadas y diálogos compartidos desde Sudamérica (pp. 497-516). Santiago: Newgrafic y Cia Ltda.

Albornoz, X. (2016). Plantas sagradas en grupos del norte semiárido, un contexto Diaguita-Inca. (Memoria para optar al título de Arqueóloga). Facultad de Patrimonio Cultural y Educación. Universidad SEK. Santiago.

Aldunate, C. (1989). Estadio Alfarero en el sur de Chile (500 a ca.1800 d.C.). En Hidalgo, J., Schiappacasse, V., Niemeyer, H., Aldunate, C., \& Solimano, I. (Eds.), Prehistoria. Desde sus orígenes hasta los albores de la conquista (pp. 329-348). Santiago: Editorial Andrés Bello.

Alfaro, S. (2013). Análisis cerámico pipas sitio La Granja. Informe Proyecto Fondecyt 1121097, primer año. Santiago: Conicyt. Manuscrito.

Alfaro, S. (2015). Análisis cerámico pipas zona sur. Informe Proyecto Fondecyt 1121097, tercer año. Manuscrito. Santiago: Conicyt. Manuscrito.

Augusta, F. J. de. (1916). Diccionario araucano-español y español-araucano. Santiago: Imprenta Universitaria.

Babot, M. P. (2007). Granos de almidón en contextos arqueológicos: posibilidades y perspectivas a partir de casos del noroeste argentino. En Marconetto, B., Oliszewski, N., \& Babot, M. P. (Eds.), Paleoetnobotánica del cono sur: estudios de casos y propuestas metodológicas (pp. 95-125). Córdoba: Universidad Nacional de Córdoba.

Belmar, C., Quiroz, L., Niemeyer, H. M., Planella, M. T., Albornoz, X., Meneses, F., Alfaro, S., Carrasco, C., Collao-Alvarado, K., \& Echeverría, J. (2014). Condiciones previas para el uso de marcadores arqueobotánicos y químicos en estudios arqueológicos sobre Complejos Fumatorios: una propuesta de protocolo para manipulación del objeto y toma de muestras. Intersecciones Antropología, 15, 497-501.

Belmar, C., Albornoz, X., Alfaro, S., Meneses, F., Carrasco, C., Quiroz, L., Babot, M. P., \& Planella, M. T. (2016). Reconstruyendo las prácticas fumatorias del sitio La Granja (130 a 1000 d.C., valle del río Cachapoal, VI región, Chile central) a partir de los microfósiles. Chungara Revista de Antropología Chilena, 48(1), 53-72.

Berdichewsky, B. (1968). Excavaciones en la cueva de los Catalanes (Provincia de Malleco). Boletín de Prehistoria de Chile, 1, 33-83.

Becker, C. (1997). Zooarqueología y etnohistoria: un contraste en la isla Mocha. En Quiroz, D., \& Sánchez, M. (Comp.), La isla de las palabras rotas (pp. 71-85). Santiago: Ediciones de la Biblioteca Nacional de Chile. Bracchitta, D., \& Seguel, R. (2009). Informe de intervención. Estudio e intervención de los materiales arqueológicos provenientes del sitio Villa JMC1, Labranza. Temuco, IX región de la Araucanía. Santiago: CNCR - DIBAM. Manuscrito.

Bullock, D. (1944). Algunos tipos de cachimbas antiguas chilenas. Boletín del Museo Nacional de Historia Natural, XXII, 147- 153.

Campbell, R. (2011). Socioeconomic differentiation, leadership and residential pattering at an Araucanian chiefly center (Isla Mocha, AD 10001700). Pittsburgh: University of Pittsburgh.

Campbell, R., \& D. Quiroz. (2015). Database dates.xls. Santiago. Manuscrito.

Ciprés Consultores Ltda. (2002). Plan de salvataje arqueológico By Pass Temuco sitio Km 0 Enlace Cajón. Santiago. Manuscrito.

Carrasco, C., Echeverría, J., Ballester, B., \& Niemeyer, H. M. (2015). De pipas y sustancias: costumbres fumatorias durante el período Formativo en el litoral del desierto de Atacama (norte de Chile). Latin American Antiquity, 26(2), 143-161.

Chernysheva, E. V., Korobov, D. S., Khomutova, T. E., \& Borisov, A. V. (2015). Urease activity in cultural layers at archaeological sites. Journal of Archaeological Science, 57, 24-31.

Citarella, L., recopiladora. (1995). Medicinas y Culturas en la Araucanía. Santiago: Editorial Sudamericana.

Coil, J., Korstanje, A., Archer, S., \& Harstof, C. (2003). Laboratory goals and considerations for multiple microfossil extraction in archaeology. Journal of Archaeological Science, 30, 991-1008.

Cooper, J. (1949). Stimulants and narcotics. Handbook of South American Indians, Bulletin, 143(5), 525-558.

De Augusta, F. J. (1966) [1916]. Diccionario araucanoespañol. Padre Las Casas: Editorial San Francisco.

Donoso, S. (2013). Análisis fragmentos cerámicos sitio Lomas de Chol Chol, provincia de Cautín, región de La Araucanía. Nueva Imperial. Manuscrito.

Dowling, J. (1971). Religión, chamanismo y mitología mapuche. Santiago: Editorial Universitaria.

Echeverría, J., Planella, M. T., \& Niemeyer, H. M. (2014). Nicotine in residues of smoking pipes and other artifacts of the smoking complex from an Early Ceramic period archaeological site in central Chile. Journal of archaeological science, 44, 55-60. 
Erize, E. (1987). Mapuche 1. Buenos Aires: Editorial Yepun.

Falkner, T. (1774). Descripción de la Patagonia y de las partes contiguas de la América del sur. Buenos Aires: Librería Hachette.

Faron, L. C. (1964). Hawks of the sun. Mapuche morality and its ritual attributes. Pittsburgh: University of Pittsburgh Press.

Föerster, R. (1985). Vida religiosa de los huilliches de San Juan de la Costa. Santiago: Ediciones Rehue.

Föerster, R. (1995). Introducción a la religiosidad mapuche. Santiago: Editorial Universitaria.

Föerster, R., \& Gundermann, H. (1996). Religiosidad Mapuche contemporánea: elementos introductorios. En Hidalgo, J., Schiappacasse, V., Niemeyer, H., Aldunate, C., \& Mege, P. (Eds.), Etnografía, sociedades indígenas contemporáneas y su ideología. Serie Culturas de Chile (pp. 189-240). Santiago: Editorial Andrés Bello.

Franceschi, V. R., \& Horner, H. T. Jr. (1980). Calcium oxalate crystals in plants. The Botanical Review, 46(4), 361416.

Gili, F. (2014). La práctica fumatoria en el Salar de Atacama durante el Período Formativo. (Tesis para optar al grado de Magister en Antropología con mención en Arqueología). Programa de Postgrado en Antropología, Universidad Católica del Norte y Universidad de Tarapacá.

Gili, F., Echeverría, J., Stovel, E., Deibel, M. \& Niemeyer, H.M. (2017). Las pipas en el Salar de Atacama y su inserción en el sistema de intercambio con el Noroeste de Argentina: un flujo de ideas con variantes locales. Estudios Atacameños 54, 37-64.

Guevara, T. (1911). Folklore Araucano: refranes, cuentos, cantos, procedimientos industriales, costumbres prehispanas. Santiago: Imprenta Cervantes.

Guevara, T., \& Oyarzún, A. (1912). El tabaco y las pipas prehistóricas de Chile. En Actas del XVII Congreso Internacional de Americanistas, 414-437. Buenos Aires, Argentina.

Gundermann, H. (1985). El sacrificio en el rito mapuche: un intento analítico. Chungara Revista Chilena de Antropología, 15, 169-195.

Haslam, M. (2004). The composition of starch grains in soils: implications for archaeological analysis. Journal of Archaeological Sciences, 31, 1715-1734.

Hermosilla, N. (2006). Informe preliminar caracterización arqueológica sitio Lomas de Chol Chol-1, proyecto Planta de tratamiento de aguas servidas Nueva Imperial, comuna de Nueva Imperial, IX región de La Araucanía. Nueva Imperial. Centro de Documentación del Consejo de Monumentos Nacionales. Manuscrito.

Hilger, M. I. (1957). Araucanian childlife and its cultural background. Washington, D.C.: Smithsonian Miscellaneous Collections.

Housse, E. (1940). Una epopeya india. Santiago: Editorial ZigZag.

Joseph, C. (1930). Antigüedades de Araucania. Revista Universitaria XV(9), 1-67.

Joseph, C. (1931). La vivienda araucana. Anales de la Universidad de Chile Año 1. Prensas de la Universidad de Chile.

ICSN. (2011). The International Code for Starch Nomenclature, (http://fossilfarm.org/ICSN/Code.html), accessed (enero 2012).

Korstanje, M. A., \& Babot. M. P. (2007). A microfossil characterization from South American economic plants. En Madella, M., \& Zurro, D. (Eds.), Plants, people and Places: recent studies in phytholithic analysis (pp. 41-72). Oxford: Oxbow Books.

Latcham, R. E. (1924). La organización social y las creencias religiosas de los antiguos Araucanos. Publicaciones del Museo de Etnología y Antropología, 3(2-4), 245-868.

Latcham, R. (1936). La agricultura precolombiana en Chile y los países vecinos. Santiago: Editorial Universitaria.

Loy, T. (1994). Methods in the analysis of starch residues on prehistoric stone tools. En Hather, J. (Ed.), Tropical archaeobotany: applications and new development (pp. 86-114). New York: Routledge.

Madella, M., Alexandre, A., \& Ball, T. (2005). International code for phytolith nomenclature 1.0. Annals of Botany, 96(2), 253-260.

Martinic M. (1991). El hábito de fumar entre los Aonikenk. Anales del Instituto de la Patagonia, 20, 19-28.

Matisoo-Smith, E., Ramírez, J. M., Quiroz, D., Seelenfreund, A., Knapp, M., \& Walter, R. (2011). Proyecto "Redrawing the Polynesian triangle", Marsden Fund. Wellington: The Royal Society of New Zealand.

Medina, J. T. (1898). Los aborígenes de Chile. Santiago: Imprenta Universitaria.

Menghin, O. (1962). Estudios de prehistoria araucana. Studia Prehistórica II. Buenos Aires: Centro Argentino de Estudios Prehistóricos.

Mera, R. (2014). Nuevos aportes al estudio del Complejo Pitrén, a partir del análisis del sitio Villa JMC-1, Labranza. (Memoria para optar al título de Arqueólogo). Departamento de Antropología, Facultad de Ciencias Sociales, Universidad de Chile.

Mera, R. \& Munita, D. (2006). Escuela Collico, un cementerio alfarero temprano en la cuenca de Valdivia. Aportes a la 
discusión del Complejo Pitrén. Boletín de la Sociedad Chilena de Arqueología, 39, 51-68.

Mera, R., \& Munita, D. (2008). Informe ejecutivo del rescate del sitio Villa JMC-1. Labranza, Comuna de Temuco, Provincia de Cautín, región de la Araucanía. Temuco. Centro de Documentación del Consejo de Monumentos Nacionales. Manuscrito.

Mera, R., \& Munita, D. (2015). Informe preliminar de rescate arqueológico Sitio Millahuillín 1. Valdivia. Centro de Documentación del Consejo de Monumentos Nacionales. Manuscrito.

Mera, R, Munita, D., \& S. Urbina. (2013). Trabajos arqueológicos en el sitio Millahuillín 1, comuna de Máfil, Provincia de Valdivia, región de Los Ríos. Informe ejecutivo. Valdivia. Centro de Documentación del Consejo de Monumentos Nacionales. Manuscrito.

Mera, R., Mille, B., Munita, D., \& Figueroa, V. (2015). Copper earrings in La Araucanía: earliest evidence of metal usage in southern Chile. Latin American Antiquity, 26(1), 106-119.

Métraux, A. (1942). The native tribes of Eastern Bolivia and Western Matto Grosso. Smithsonian Institution, Bureau of American Ethnology, 134. Washington: United States Government Printing Office.

Möesbach, E. (1992) [1959]. Botánica indigena de Chile. Santiago: Editorial Andrés Bello.

Molina, J. I. (2000) [1788]. Compendio de la historia geográfica, natural y civil del Reyno de Chile. Biblioteca del Bicentenario. Santiago: Pehuén Editores.

Munita, D., Mera, R., Figueroa, V., \& Mille, B. (2011). Evidencias tempranas del trabajo de metales en La Araucanía. Adornos de cobre en el complejo Pitrén. En Actas del $2^{\circ}$ Congreso Latinoamericano de Arqueometría, 87-100. Lima, Perú.

Nardi, R. (1981-1982). Los Mapuche en la Argentina. Esquema Etnohistórico. En Cultura Mapuche en La Argentina (pp. 11-24). Buenos Aires: Museo Nacional del Hombre, Instituto Nacional de Antropología y Pensamiento Latinoamericano (INAPL).

Núñez de Pineda y Bascuñán, F. (1863)[1637]. Cautiverio feliz, y razón de las guerras dilatadas de Chile. Colección de historiadores de Chile y documentos relativos a Historia Nacional, Tomo III. Santiago: Imprenta del Ferrocarril.

Ocampo, C., Mera R., \& Munita, D. (2005). Antecedentes arqueológicos prehispánicos para la ruka mapuche: El sitio "Km 0 - Enlace Cajón, By Pass Temuco". En Actas del XVI Congreso Nacional de Arqueología Chilena, 193-202. Tomé, Chile.
Ocampo, C., Mera, R., \& Rivas, P. (2004). Cementerios Pitrén en el By pass de Temuco. En Actas del IV Congreso Chileno de Antropología, Tomo 2, 1465-1472. Santiago, Chile.

Quizóz, D., \& Olivares, J. C. (1987). Permanencia de una pauta adaptativa en San Juan de la Costa. Boletín del Museo Mapuche de Cañete, 3, 13-26.

Ortiz, O. (1968). Descripción de un conjunto de pipas indígenas del Sur de Chile. Antropología 1, 1-25

Pearsall, D. (2009). Paleoethnobotany: a handbook of procedures, Second Edition. Walnut Creek: Left Coast Press Inc.

Peralta, P. (2008). Informe de análisis lítico sitio Lomas de Chol Chol IX región de La Araucanía. Nueva Imperial. Manuscrito.

Piperno, D. (2006). Phytoliths: a comprehensive guide for archaeologists and paleoecologists. Oxford: Rowman Altamira.

Planella M. T., Falabella, F., Tagle, B. y Manríquez, V. (1997). Informe final Proyecto Fondecyt 1940457. Santiago: Conicyt. Manuscrito.

Planella, M. T, Falabella, F., Manriquez, V., \&Tagle, B. (1995). Fundamentos prehispanos de la población "Promaucae" Histórica. Informe proyecto Fondecyt 1940457, primer año. Santiago: Conicyt. Manuscrito.

Planella, M. T., Belmar, C., Quiroz, L., \& Estévez, D. (2012) Propuesta integradora para un estudio del uso de plantas con propiedades psicoactivas en pipas del periodo Alfarero Temprano y sus implicancias sociales. Revista de Antropología Chilena, 25(1), 93-119.

Planella, M. T., Belmar, C., Quiroz, L., Falabella, F., Alfaro, S., Echeverría, J., \& Niemeyer, H. M. (2016). Towards the reconstruction of the ritual expressions of societies of the Early Ceramic Period in central Chile: social and cultural contexts associated with the use of smoking pipes. En Bollwerk, E., \& Tushingham, S. (Eds.), Perspectives on the archaeology of pipes. tobacco and other smoke plants in the ancient Americas. (pp. 231-254). Springer.

Plowman, T., Gyllenhaal, L. O. y., \& Lindgren, J. E. (1971). Latua pubiflora. Magic plant from southern Chile. Botanical Museum Leaflets, Harvard University, 23.

Prieto, X. (1997). Evolución geomorfológica de la isla Mocha durante el Holoceno. En Quiroz, D. y Sánchez, M. (Comp.), La isla de las palabras rotas (pp. 87-101). Santiago: Ediciones de la Biblioteca Nacional de Chile.

Quiroz, D., \& Sánchez, M. (Comp.). (1997). La isla de las palabras rotas. Santiago: Ediciones de la Biblioteca Nacional de Chile. 
Quiroz, L. (2014). Colección de referencia de microrrestos de las especies nativas del género Nicotiana en Chile: El caso específico de los tricomas y su morfometría. En Inda, H. (Ed), Libro de resúmenes taller "Micro Paleoetnobotánica" relevancia de una red interdisciplinaria de investigaciones en fitolitos y almidones (pp. 59-63). La Paloma, Uruguay.

Quiroz, L., Belmar, C., Planella, M. T., Mera, R., \& Munita. D. (2012). Estudio de microfósiles de residuos adheridos en pipas cerámicas del sitio Villa JMC1 Labranza, región de la Araucanía. Magallania, 40(1), 249-261.

Quiroz. L., Belmar, C., Planella, M. T, Niemeyer, H. M., Albornoz, X., \& Meneses, F. (2015). Colección de referencia de microrrestos de las especies nativas del género Nicotiana en Chile. En Belmar, C., \& Lema V. (Eds.) Avances y desafíos metodológicos en arqueobotánica: miradas consensuadas y diálogos compartidos desde Sudamérica (pp. 517-531). Santiago: Newgrafic y Cia Ltda.

Quiroz, L., Alfaro, S., Planella, M. T., Belmar, C., Echeverría, J., Niemeyer, H. M., Meneses, F., Albornoz, X., Carrasco, C., \& Thielemann, B. (2016). De pipas, complejos y prácticas fumatorias en el periodo Alfarero Temprano del norte semiárido. Manuscrito.
Reichert, E. (1913). The differentiation and specificity of starches in relation to Genera, Species etc. Stereochemistry applied to protoplasmic processes and products, and as a strictly scientific basis for the classification of plants and animals, Publication $n^{\circ} 173$. Washington D.C.: Carnegie Institution.

Rosales, D. (1877-1878). Historia general del Reino de Chile. Valparaíso: Imprenta El Mercurio.

Saerens, S. M. G., Delvaux, F., Verstrepen, K. J., Van Dijck, P., Thevelein, J. M., \& Delvaux, F. R. (2008). Parameters affecting ethyl ester production by Saccharomyces cerevisiae during fermentation. Applied and environmental microbiology, 74(2), 454-461.

Sanhueza, J. (1989). Proyectos de investigación e informes de avance. Zona Sur. Boletín de la Sociedad Chilena de Arqueología, 10, 5-6.

Serrano, A. (1934). El uso del tabaco y vegetales narcotizantes entre los indígenas de América. Revista geográfica Americana, II(15), 415-425.

Titiev, M. (1965). Araucanian culture in transition. New York: University of Michigan Press.

Westfall, C. (1993-1994). Pipas prehispánicas de Chile. Revista Chilena de Antropología, 12, 123-161.

Wilbert, J. (1987). Tobacco and shamanism in South America. New Haven: Yale University Press. 